\title{
The Joint Optimal Allocation Study of Regional Total Water Consumption and Pollutant Carrying Capacity of Water Function Areas Based on Emergy Theory
}

\author{
Xi Guo ${ }^{1}$, Zening $\mathrm{Wu}^{1}$, Xinling Wang ${ }^{2}$, Cuimei $\mathrm{Lv}^{1, *}$, Changkuan $\mathrm{Gu}^{3}$, Yang $\mathrm{Li}^{3}$ and \\ Meiyan Gao ${ }^{1}$ \\ 1 School of Water Conservancy Engineering, Zhengzhou University, Zhengzhou 450001, China \\ 2 School of Civil Engineering, Zhengzhou University, Zhengzhou 450001, China; xinlingwang@zzu.edu.cn \\ 3 Kaifeng Hydrology and Water Resources Survey Bureau, Kaifeng 475000, Henan, China \\ * Correspondence: lvcuimei305@163.com; Tel.: +86-15136202036
}

Received: 19 February 2020; Accepted: 10 April 2020; Published: 13 April 2020

\begin{abstract}
How to allocate the limited water consumption and pollutant carrying capacity of water function areas to sub-areas and water sectors is key for the practice of the most stringent water resource management decision-making. In response to the joint optimal allocation mechanism of water consumption and pollutant-carrying capacity, joint optimal allocation and the unified quantification problem of multiform benefits, the whole process of joint optimal distribution is refined into the links "water supply—water use and consumption—drainage-pollutant carrying" and the unified quantification method based on the emergy theory to achieve various economic, social, and ecological benefits in different links is proposed. Then the joint optimal allocation joint optimal allocation model of regional water consumption and pollutant carrying capacity is constructed, which realizes the reverse constraint relationship between water quantity and pollution carrying capacity in the water quality and quantity conversion processes. Using Zhengzhou city as an example, the models and methods were applied and researched. Countermeasures and suggestions for the rational allocation of available water resources and water pollution capacity were put forward accordingly.
\end{abstract}

Keywords: water resource management; joint optimal allocation; pollutant carrying capacity; emergy analysis

\section{Introduction}

According to the most stringent water resource management system, the total amount of control exercisable over water resources and the benefit of such control over water use and the pollutant carrying capacity limits of the water function area must be implemented simultaneously in the process of water resource utilization and protection [1-3]. Given the whole process of "water supply-water use and consumption-drainage-pollutant carrying," the available water quantity is closely related to the pollutants in the river, and the total amount of pollutants in the river is interrelated with sewage discharge. At the same time, sewage discharge is also related to the allocation of domestic water, production water, and ecological water, as well as the benefit of using water. This requires that the water distribution, water function zone assimilative capacity distribution, and water use benefit improvements be unified across water resources in order to optimize allocation.

Therefore, the joint optimal allocation of water consumption and pollutant carrying capacity is essentially a manual regulation that realizes the reverse constraint relationship between water quantity and pollution carrying capacity in the water quality and quantity conversion processes in order to control the water consumption quantity from the source water supply link and the total pollutants 
amount into the river from terminal drainage link, and meet the requirements of available water supply of water sources and pollutant carrying capacity of the water functional area at the same time. Then, the water use efficiency is improved and the reasonable distribution of the limited water consumption and pollutant carrying capacity is realized.

Additionally, several imperfections exist in the current related research on the joint optimal allocation of water quality and water quantity. Yan et al. [4] proposed the technical framework for a dual cross control study of rivers based on the reasonable allocation of water resources from the water quantity control layer and the water quality control layer. However, this study only meets the total pollutant carrying capacity constraints of the water function area from the point of total amount control. It is difficult to guarantee the pollutant carrying capacity restrictions of water function zoning. Liu et al. [5] regarded both water withdrawal and pollutant discharge as control indexes, and constructed the multi-objective model for optimal allocation of water resources in based on dual-control of water quality and quantity. However, this water quality target is difficult to ensure that the minimum pollutants discharge into the river is within the pollutant carrying capacity range of the water function area. You et al. [6] summarized the regulation idea and research progress of unified regulation of water quantity and quality and pointed out that there are few research studies on unified regulation of water quantity and quality aiming at decision support at present, and put forward the total quantity regulation idea aiming at pollution control, water quantity allocation, and water ecological protection. Fan et al. [7] proposed the overall idea that the study water demand threshold through total pollution carrying capacity control, starting from the carrying capacity of water environment, which deduced the maximum water demand of the basin, according to pollution carrying capacity. However, as long as the water requirement threshold is met, it is regarded as the control index of total pollution carrying capacity. Zhang [8] took water resources utilization, water efficiency, and total pollution discharge into the river as a control target simultaneously, and constructed the optimization allocation of water quantity and quality based on life cycle theory of water resources. However, it cannot realize the allocation of pollutant carrying capacity in each sub-area as the same as the water quantity element. The ecological and economic impacts after pollutants into the river are not considered in the target selection. Therefore, the joint distribution benefits cannot be reflected fully.

In summary, the current state of integrated optimal allocation of water quality and water quantity still exists the following problems that need further study: (1) Configuration elements. The normal configuration mainly focuses on the water quantity allocation among different users, while water-quality factors have generally been simplified. However, it is difficult to ensure that pollutant emissions meet the pollutant carrying capacity limits of each water function area, and lacks the handling analysis for pollutant reduction and the mutual restriction mechanism study of water quantity and pollutant carrying capacity. (2) Configuration model. Configuration mainly uses the multi-objective model, but it is difficult to achieve the target of economic, social, and ecological environments-that is, for a uniform measurement-because they have different forms and dimensions. Thus, the weighted method is usually adopted to transfer the multiple objectives into a single objective, but its subjectivity is too strong to ensure that the configuration results accord with reality.

To sum up, the purpose of the work is to realize the joint distribution of total water consumption and pollutant carrying capacity of water functional areas from the perspective of eco-economics. Therefore, this paper builds the coupling relationship among water consumption, sewage discharge, and pollutants discharged into rivers, proposes the expression form and calculation method of various benefits in "water supply—water use and consumption-drainage-pollutant carrying" links, which simultaneously takes water consumption and pollutant carrying capacity in water functions as decision-making variables, and achieves the maximum net benefit in the process of joint distribution as an objective function in order to establish the joint optimal allocation model of the total water consumption and pollutant carrying capacity based on emergy theory. 


\section{Material and Methods}

\subsection{The Emergy Analysis of the Benefits of Joint Optimal Allocation of Water Consumption and Pollutant Carrying Capacity}

The water resource eco-economic system transforms the water resources system, ecological environment system, and social economic system into an indispensable organic component of its internal structure and operation. Then, water resource utilization and protection, and the organic connection between water resources and other economic and natural resources, are emphatically focused on. However, as a multi-objective service for the natural and social economy, water resources not only support economic and social development, but also satisfy the stability of the ecological system [9]. The benefits of integrating the distribution of water consumption and pollutant carrying capacity are accompanied by the circulation process of "water supply-water consumption-drainage-pollutant carrying." Therefore, in contrast to the target benefit of traditional water allocation methods, the benefits of joint optimal allocation not only needs to consider the economic, social, and ecological environment benefits of the water consumption link, but must also consider the environmental damage caused by sewage and the cost of maintaining ecological health in drainage and pollutant carrying links.

\subsubsection{The Component of Joint Optimal Allocation Benefits}

(1) Benefits of the water supply link

In the water supply link, dams and ponds are built to store water resources, reservoirs, and diversion projects that are built to develop water resources. Water plants and purified water plants are built to purify water bodies. In summary, the main purpose of the water supply link is to introduce natural water bodies into socio-economic systems, and to form engineering water bodies that are affected by construction works, which can be used by the water consumption link. Therefore, the benefits of the water supply link are shown in the supply of engineering water, which is used by various water use sectors, and belong to the category of ecological environmental benefits.

(2) Benefits of water use and the consumption link

In the water use and consumption links, as production materials, water resources provide power and raw materials for economic and social production, such as agricultural water, industrial water, hydroelectric power generation, shipping, and so on, and reflects the positive economic benefits of water resources utilization. As domestic materials, water resources provide drinking water for human beings and other animals in order to maintain domestic health, which brings the positive social benefit of water resources utilization [10]. As ecological materials, water resources are used for urban greening, environmental sanitation, river and lake hydration, and plays an irreplaceable role in regulating the climate, purifying the environment, fixing carbon, releasing oxygen, improving social welfare, and more. This creates the positive ecological and environmental benefit of water resource utilization. Therefore, due to the different sectors of water use, the corresponding forms of various benefits are different, and it is difficult to achieve a unified measurement.

(3) Benefits of the drainage link

In the drainage link, the sewage produced by agricultural water and domestic rural water are discharged into the natural ecosystem directly. It not only reduces the water quality and destroys the water environment, but also makes the originally available water resources lose their use value [9], which reflects the negative ecological-environment effects. The sewage from domestic urban water and industrial water are usually discharged into the natural water body or are reused after the treatment of sewage treatment projects. This process requires a lot of economic investment, such as energy consumption, pharmaceutical consumption, maintenance costs, personnel costs, and more, and brings corresponding negative economic effects. 
(4) Benefits of the pollutant-carrying link

In the pollutant-carrying link, although sewage treatment in most regions of China have implemented the discharge standard, the amount of pollutants discharged into rivers after treatment still cannot meet the requirements of the restriction on the amount of pollutants in a regional water function area. On the one hand, we can add new sewage treatment systems in order to reduce the pollutants that exceed the pollutant carrying capacity of water function areas [11], so as to reduce the chemical energy of sewage. On the other hand, we can start from the source and control the water supply quantity of water sectors, which reduces the sewage amount directly. Lastly, it is also possible to improve water use efficiency, adjust the industrial structure, and reduce the pollutant discharge coefficient. The economic investment of these pollutant-carrying measures has negative economic effects. In summary, in the process of integrating the distribution of water consumption and the pollutant carrying capacity, the water cycle of different links in different water sectors show the different types and forms of benefits, which cover the positive and negative economic, social, and ecological environment effects. They are independent and self-contained, but interact with each other due to the circulation and flow of water.

\subsubsection{Emergy Quantification Method for Joint Optimal Allocation Benefits}

The benefits analysis of the integrated optimal distribution of regional water consumption and pollutant carrying capacity shows that the forms and dimensions of benefits are different. It is difficult for the traditional evaluation method to achieve a unified quantitative evaluation. Emergy analysis is a quantitative research method in the process of the ecological economic system, which can transform all kinds of materials with different levels of energy and money being put into the solar energy value, and the unified measurement of various materials and energies is realized [12]. Emergy is the energy amount of another category contained in the fluid or stored energy. There is a transformational relationship between energies of different qualities-emergy transformity, namely the contained amount of another energy that forms per unit of matter or energy [9]. Due to various energies being derived from solar energy directly or indirectly, the emergy analysis converts different types of energy that cannot be compared into the same standard. Solar emergy's unit is solar emjoules. The abbreviation is sej.

Therefore, environmental factors, production factors, technological factors, and economic indicators can be transformed into the same "emergy", and emergy analysis is applied to calculate all the integrated optimal distribution efficiencies, either directly or indirectly.

Emergy Quantification of Benefits in the Water Supply Link

The benefits of the water supply link mainly manifested as the engineering water supply benefits $\left(E M_{S}\right)$. Engineering water refers to the water body after water conservancy engineering measures such as water storage, water diversion, water extraction, and water diversion, which can be used by users directly. From the perspective of emergy, it can be seen as economic and social activity contributions to a natural water body. Therefore, the transformity of the natural water body has been changed. Therefore, the calculation of the water supply benefits can be calculated by the difference in the transformity before and after the water supply link. The calculation formula is as follows.

$$
E M_{s}=\left(\tau_{g w}-\tau_{m w}\right) \times W_{s}
$$

In the formula, $E M_{S}$ is the benefits of the water supply link, sej. $\tau_{g w}$ is the transformity of the engineering water body, sej $/ \mathrm{m}^{3} . \tau_{m w}$ is the transformity of the natural water body, sej $/ \mathrm{m}^{3}$, and $W_{s}$ is the supply amount of the engineering water, $\mathrm{m}^{3}$.

Emergy Quantification of Benefits in Water Use and the Consumption Link

(1) Industrial water use and the consumption link 
The benefits of industrial water use and consumption is mainly shown as industrial product benefits $\left(E M_{p i}\right)$, which reflect the contribution share of water as a production factor in industrial economic activities. It can be calculated by the result of the water resources industrial contribution ratio and the emergy output of the industrial production system. The calculation formula is as follows.

$$
\begin{gathered}
E M_{p i}=\sigma_{i} \times E M_{o i} \\
\sigma_{i}=\frac{E M_{w i}}{E M_{t i}}
\end{gathered}
$$

In the formula, $E M_{p i}$ is the industrial products benefits, sej. $E M_{o i}$ is the total output emergy of the system, sej. $\sigma_{i}$ is the water resources industrial contribution ratio, as a percentage. $E M_{w i}$ is the input emergy of industrial water, sej, and $E M_{t i}$ is the total input emergy of the industrial system, sej.

(2) Agricultural water use and the consumption link

The benefits of agricultural water use and consumption is mainly shown as agricultural product benefits $\left(E M_{p a}\right)$. The agricultural product benefits are similar to the industrial product benefits using the water resource agricultural contribution ratio, and are calculated from the contribution quantity of water resources to agricultural production [13]. The calculation formula is as follows.

$$
\begin{aligned}
E M_{p a} & =\sigma_{a} \times E M_{o a} \\
\sigma_{a} & =\frac{E M_{w a}}{E M_{t a}}
\end{aligned}
$$

In the formula, $E M_{p a}$ is the agricultural product's benefits, sej. $E M_{o a}$ is the total output emergy of the agricultural system, sej. $\sigma_{a}$ is the water resource agricultural contribution ratio, as a percentage. $E M_{w a}$ is the input emergy of the agricultural water, sej, and $E M_{t a}$ is the total input emergy of the agricultural system, sej.

(3) Domestic water use and the consumption link

The benefits of domestic water use and consumption are mainly reflected as the labor recovery benefit $\left(E M_{l r}\right)$. The domestic water process should be considered to be the input-output process of water resources, and the output emergy should be replaced with a per capita disposable income, which is the most representative of real-life conditions. Then, by multiplying the water resource domestic contribution ratio, the emergy output of domestic water and the Engel coefficient can be found, which are the labor recovery benefits of water resources. The calculation formula is as follows.

$$
\begin{gathered}
E M_{l r}=\sigma_{d} \times E M_{o d} \times E . \\
\sigma_{d}=\frac{E M_{w d}}{E M_{t d}}
\end{gathered}
$$

In the formula, $E M_{l r}$ represents the labor recovery benefit, sej. $E M_{o d}$ is the emergy output of domestic water, sej. $\sigma_{a}$ is the water resources domestic contribution ratio, as a percentage. $E$ is the Engel coefficient, as a percentage. $E M_{w d}$ is the input emergy of domestic water, sej, and $E M_{t d}$ is the total input emergy of the domestic system, sej.

(4) Ecological water use and the consumption link

a. Dilution of the purification benefits

The artificial replenishment of lakes and wetlands through water diversion and water transfers can effectively alleviate the phenomenon of "more evaporation and less replenishment." In addition, it can achieve the effects of diluting and purifying water bodies and improving ecological environments [14]. Therefore, the dilution purification benefits can be estimated by multiplying the artificial water 
replenishment amount in lakes and wetlands by the transformity of the water body. The calculation formula is as follows.

$$
E M_{d c}=W_{r} \times \tau_{r}
$$

In the formula, $E M_{d c}$ is the dilution purification benefit, sej. $W_{r}$ is the artificial replenishment amount in the rivers and lakes, $\mathrm{m}^{3}$, and $\tau_{r}$ is the transformity of the artificial replenishment water, sej $/ \mathrm{m}^{3}$.

\section{b. Cooling and humidifying benefits}

The cooling and humidifying benefits mainly consider the benefits of the ecological water used for urban greening and road spraying. Most of them evaporate into the air, increase the air humidity, absorb a large amount of heat, and cause local temperature drops. When calculating the cooling and humidifying benefits, this part of the ecological water is considered to be used for evapotranspiration. The calculation formula is as follows.

$$
\begin{gathered}
E M_{c h}=W_{g} \times L \times \tau_{r} \\
L=2507.4-2.39 T
\end{gathered}
$$

In the formula, $E M_{c h}$ is the cooling and humidifying benefits, sej. $L$ is the latent heat of evaporation, $\mathrm{J} / \mathrm{g}$. $T$ is the calculated regional average temperature, ${ }^{\circ} \mathrm{C} . W_{g}$ is the ecological water amount for urban greening and road spraying, $\mathrm{g}$, and $\tau_{s}$ is the steam transformity, sej/J.

c. Carbon fixation and oxygen release benefits

The carbon fixation and oxygen release benefits of green plants in urban greening are reflected in the amount of $\mathrm{CO}_{2}$ fixed and the oxygen released by green plants through the artificial water supply. The calculation formula is as follows.

$$
E M_{c o}=\left(G_{c O_{2}} \times \tau_{c 0_{2}}-G_{o_{2}} \times \tau_{o_{2}}\right) \times \frac{W_{g}}{W_{p}} .
$$

In the formula, $E M_{c o}$ is the carbon fixation and oxygen release benefits, sej. $G_{c_{2} 2_{2}}$. and $G_{O_{2}}$. are the annual carbon fixation and oxygen release of green vegetation in an artificial aquatic ecosystem, respectively, $\mathrm{kg} . \tau_{\mathrm{CO}_{2}}$ and $\tau_{\mathrm{O}_{2}}$ are the transformity of $\mathrm{CO}_{2}$ and $\mathrm{O}_{2}$, sej/kg. $W_{g}$ is green water consumption, $\mathrm{m}^{3}$, and $W_{p}$ is the natural precipitation replenishment, $\mathrm{m}^{3}$.

d. Spraying and dust removal benefits

Dust emissions from construction sites are one of the most important factors that affect urban environments and cause haziness. Spraying on urban roads can effectively curb dust emissions from roads and construction sites, improve air quality, and increase atmospheric visibility. The main components of dust from construction sites are cement, sand, and other materials, and the control efficiency of sprinkling water on cement and sand materials is $48.62 \%$ [15]. Due to the limited spraying height and dust removal effects, the general sprinkler only works on the sedimentation of PM10 below $5 \mathrm{~m}$ of the surface. The cement particle size is much smaller than the sand particle size [16]. Therefore, the cement dust is the main component that causes the increase of PM10. From an emergy perspective, the formula for dust removal benefits of urban road spraying is as follows.

$$
E M_{s d}=A \times h \times \Delta P M_{10} \times \tau_{n} \times 48.62 \% .
$$

In the formula, $E M_{s d}$ is the spraying and dust removal benefits, sej. $A$ is the proportion of study area, $\mathrm{m}^{2} . h$ is the height of sprinkling water, $\mathrm{m} . \Delta P M_{10}$ is the variable quantity of PM10 in the calculation period, $\mu \mathrm{g} / \mathrm{m}^{3}$, and $\tau_{n}$ is the transformity of cement, which is $1.98 \times 10^{3} \mathrm{sej} / \mu \mathrm{g}$ [17]. 
Emergy Quantification of Benefits of the Drainage Link

There is no drainage or pollutant-carrying link in the ecological water use and consumption sectors. Therefore, this part only considers industrial drainage, agricultural drainage, and domestic drainage.

(1) Industrial drainage link

The negative benefits of the industrial drainage link are mainly reflected as the loss of industrial wastewater treatment $\left(E M_{i s}\right)$. Industrial wastewater needs to be treated by the sewage treatment plant in order to ensure that the treated wastewater meets the discharge standards. Based on eco-economic values, in order to reduce the value loss of water resources, caused by water pollution in the drainage link, some treatment measures have been adopted to remove the pollutants. Therefore, the negative effects of this link can be measured by the sewage treatment cost [18], which refers to the operation cost of treating a certain amount of sewage by the existing sewage treatment projects. The calculation formula is as follows.

$$
E M_{i s}=W_{i s} \times U T C \times E D R .
$$

In the formula, $E M_{i s}$ is the loss of industrial wastewater treatment, sej. $W_{i s}$ is the discharge of industrial wastewater, t. UTC is the unit wastewater treatment cost, 10,000 yuan/t, and EDR is the regional emergy/currency ratio, sej/yuan.

(2) Agricultural drainage link

The negative effects of the agricultural drainage link are mainly reflected by the water quality pollution loss caused by the direct discharge of agricultural drainage $\left(E M_{a d}\right)$. The water quality pollution loss refers to the loss amount caused by untreated agricultural wastewater discharged into the natural ecological environment, which destroys the proper service function of a water body, including water, soil, and air pollution caused by chemical fertilizer being used in planting, and environmental loss caused by aquaculture wastewater in agriculture and animal husbandry. In terms of emergy, the biggest difference between sewage and clean water is the transformity [19-21] because the agricultural production process cleans the water, changes its transformity, and turns it into sewage. Therefore, the water quality pollution loss caused by the direct discharge of wastewater can be calculated by the difference in the transformity between sewage and the pre-polluted water. The calculation formula is as follows.

$$
E M_{a d}=\left(\tau_{w a}-\tau_{w b}\right) \times W_{a d} .
$$

In the formula, $E M_{a d}$ is the water quality pollution loss caused by the direct discharge of agricultural drainage water, sej. $\tau_{w a}$ is the transformity of pre-polluted water, sej $/ \mathrm{m}^{3} . \tau_{w b}$ is the transformity of sewage, sej $/ \mathrm{m}^{3}$, and $W_{a d}$ is the amount of untreated agricultural wastewater, $\mathrm{m}^{3}$.

(3) Domestic drainage link

a. The sewage treatment loss of urban domestic $\left(E M_{d s}\right)$ sewage

Urban domestic sewage is treated in a sewage treatment plant so that the treated sewage can meet the discharge standards or the water quality requirements for reuse. The loss of urban domestic sewage treatment refers to the operation costs of treating a certain amount of sewage by using the existing sewage treatment project. The calculation formula is as follows.

$$
E M_{d s}=W_{d s} \times U T C \times E D R
$$

In the formula, $E M_{d s}$ is the sewage treatment loss of urban domestic sewage, sej. $W_{d s}$ is the discharge of urban domestic sewage, $t$. UTC is the unit sewage treatment cost, 10,000 yuan/t, and EDR is the regional emergy: currency ratio, sej/yuan.

b. The water quality pollution loss of rural domestic $\left(E M_{d d}\right)$ sewage 
This refers to the loss amount caused by untreated rural domestic sewage that is discharged into the natural ecological environment, which destroys the service function of a water body. Its calculation method is similar to the negative effects of the agricultural drainage link.

$$
E M_{d d}=\left(\tau_{w a}-\tau_{w b}\right) \times W_{d d} .
$$

In the formula, $E M_{d d}$ is the water quality pollution loss caused by the direct discharge of rural domestic sewage, sej. $\tau_{w a}$ is the transformity of pre-polluted water, sej $/ \mathrm{m}^{3} . \tau_{w b}$ is the transformity of sewage, sej $/ \mathrm{m}^{3}$, and $W_{d d}$ is the discharge amount of untreated rural domestic sewage, $\mathrm{m}^{3}$.

\section{Emergy Quantification of Benefits in the Pollutant Carrying Link}

Due to the randomness and extensiveness of agricultural, non-point source pollution, the traditional reduction methods for end-pollutants cannot work adequately. Therefore, the engineering measures input into the pollutant-carrying link do not consider the agricultural water sector and rural domestic water sector. The benefits of the pollutant-carrying link mainly consider the industrial water sector and urban domestic water sector.

(1) Industrial water pollutant-carrying link

The negative effects of the industrial water pollutant-carrying link are mainly reflected as the pollutant reduction costs in the industrial water sector $\left(E M_{i p}\right)$. If the pollutant content of the industrial wastewater discharged after treatment with the current treatment is still higher than the pollutant-carrying capacity allocated by the industrial water sector, some new sewage treatment systems need to be added to reduce the pollutants and to decrease the amount of pollutants in rivers. The pollutant reduction costs refer to the engineering investment of newly added sewage treatment measures and the operating costs required to reduce a certain amount of pollutants. The unit reduction cost is assumed to only consider the relationship between the pollutant reduction amount and the cost of input, regardless of the influence of other factors. Therefore, the pollutant reduction costs are as follows.

$$
E M_{i p}=Q_{p} \times U C R_{p} \times E D R .
$$

In the formula, $E M_{i p}$ is the negative effects of industrial pollutants reduction, sej. $Q_{p}$ is the quantity of the pollutant $p$ reduced by the newly added sewage treatment measures, t. $U C R_{p}$ is the unit reduction cost of pollutants $p, 10,000$ yuan/t, and EDR is regional emergy/currency ratio, sej/yuan.

(2) Urban domestic water pollutant carrying link

The negative effects of the urban domestic water pollutant-carrying link are mainly reflected as the pollutant reduction costs in the urban domestic water sector $\left(E M_{d p}\right)$. Similar to the industrial water pollutant-carrying link, the calculation formula of the pollutant reduction costs in the urban domestic water pollutant carrying link is as follows.

$$
E M_{d p}=Q_{p} \times U C R_{p} \times E D R
$$

In the formula, $E M_{d p}$ is the negative effects of urban domestic pollutants reduction, sej. $Q_{p}$ is the quantity of the pollutant $p$ reduced by the newly added sewage treatment measures, $\mathrm{t}$. $U C R_{p}$ is the unit reduction costs of the pollutant $p, 10,000$ yuan/t, and EDR is the regional emergy/currency ratio, sej/yuan.

In summary, the specific classification and emergy quantification method of joint optimal allocation benefits of water consumption and pollutant carrying capacity is shown in Table 1. 
Table 1. The benefits composition of joint optimal allocation of water consumption and pollutant carrying capacity.

\begin{tabular}{|c|c|c|c|}
\hline Links & Water Sector & Benefits & Emergy Quantification Method \\
\hline $\begin{array}{l}\text { Water supply } \\
\text { link }\end{array}$ & $\begin{array}{l}\text { Industrial, agricultural, } \\
\text { domestic, and ecological } \\
\text { water supply }\end{array}$ & $\begin{array}{l}\text { Engineering water supply } \\
\text { benefits }(+)\end{array}$ & $E M_{s}=\left(\tau_{g w}-\tau_{m w}\right) \times W_{s}$ \\
\hline \multirow{7}{*}{$\begin{array}{l}\text { Water use and } \\
\text { the } \\
\text { consumption } \\
\text { link }\end{array}$} & $\begin{array}{l}\text { Industrial water use and } \\
\text { the consumption }\end{array}$ & Industrial product benefits $(+)$ & $E M_{p i}=b_{i} \times E M_{o i}$ \\
\hline & $\begin{array}{l}\text { Agricultural water use } \\
\text { and the consumption }\end{array}$ & $\begin{array}{l}\text { Agricultural product benefit } \\
(+)\end{array}$ & $E M_{p a}=b_{a} \times E M_{o a}$ \\
\hline & $\begin{array}{l}\text { Domestic water use and } \\
\text { the consumption }\end{array}$ & Labor recovery benefit $(+)$ & $E M_{l r}=b_{d} \times E M_{o d} \times E$ \\
\hline & \multirow{4}{*}{$\begin{array}{l}\text { Ecological water use and } \\
\text { the consumption }\end{array}$} & $\begin{array}{l}\text { Dilution of the purification } \\
\text { benefits }(+)\end{array}$ & $E M_{d c}=W_{r} \times \tau_{r}$ \\
\hline & & $\begin{array}{l}\text { Cooling and humidifying } \\
\text { benefits }(+)\end{array}$ & $E M_{c h}=W_{g} \times L \times \tau_{s}$ \\
\hline & & & $E M_{c o}=\left(G_{c_{2}} \times \tau_{c O_{2}}-G_{O_{2}} \times \tau_{o_{2}}\right) \times \frac{W_{g}}{W_{p}}$ \\
\hline & & $\begin{array}{l}\text { Spraying and dust removal } \\
\text { benefits }(+)\end{array}$ & $E M_{s d}=A \times h \times \Delta P M_{10} \times \tau_{n} \times 48.62 \%$ \\
\hline \multirow{4}{*}{ Drainage link } & Industrial drainage & $\begin{array}{l}\text { loss of industrial wastewater } \\
\text { treatment (-) }\end{array}$ & $E M_{i s}=W_{i s} \times U T C \times E D R$ \\
\hline & Agricultural drainage & $\begin{array}{l}\text { water quality pollution loss } \\
\text { caused by the direct discharge } \\
\text { of agricultural drainage (-) }\end{array}$ & $E M_{a d}=\left(\tau_{w a}-\tau_{w b}\right) \times W_{a d}$ \\
\hline & \multirow{2}{*}{ Domestic drainage } & $\begin{array}{l}\text { sewage treatment loss of } \\
\text { urban domestic }(-)\end{array}$ & $E M_{d s}=W_{d s} \times U T C \times E D R$ \\
\hline & & $\begin{array}{l}\text { water quality pollution loss of } \\
\text { rural domestic (-) }\end{array}$ & $E M_{d d}=\left(\tau_{w a}-\tau_{w b}\right) \times W_{d d}$ \\
\hline \multirow{2}{*}{$\begin{array}{l}\text { Pollutant } \\
\text { carrying link }\end{array}$} & $\begin{array}{l}\text { Industrial water } \\
\text { pollutant-carrying }\end{array}$ & $\begin{array}{l}\text { Pollutant reduction costs in } \\
\text { the industrial water sector (-) }\end{array}$ & $E M_{i p}=Q_{p} \times U C R_{p} \times E D R$ \\
\hline & $\begin{array}{l}\text { Urban domestic water } \\
\text { pollutant carrying }\end{array}$ & $\begin{array}{l}\text { Pollutant reduction costs in the } \\
\text { urban domestic water sector (-) }\end{array}$ & $E M_{d p}=Q_{p} \times U C R_{p} \times E D R$ \\
\hline
\end{tabular}

\subsection{The Joint Optimal Allocation Model of Water Consumption and Pollutant Carrying Capacity}

\subsubsection{Decision Variables}

In contrast to the traditional optimization allocation of water resources, the decision variables of macroscopic integrated optimal distribution of regional water consumption and pollutant carrying capacity includes two types: first is the quantity of water from different water sources that are allocated to different users. The other type is the pollutant-carrying capacity of different sub-regions by different users, which are allocated to different water function areas.

(1) The quantity of water from different water sources that are allocated to different sub-regions and different water sectors. $X$ was used, respectively.

$$
\begin{aligned}
& X=\left(X^{1}, X^{2}, \cdots, X^{S L}\right) \\
& X^{k}=\left(x_{i j}^{k}\right) \quad(i=1,2, \cdots, P W Y+W Y(k) ; j=1,2, \cdots, W S(k) ; k=1,2, \cdots, S L)
\end{aligned}
$$

$x_{i j}^{k}$, represents the amount of water of user $j$ in sub-region $k$, which was allocated from the water source $i$.

(2) The pollutant carrying capacity of different sectors in different sub-regions, which were allocated from different water function areas. $Y$ was used, respectively.

$$
\begin{aligned}
& Y=\left(Y^{1 p}, Y^{2 p}, \cdots, Y^{S L p}\right) \\
& Y^{k p}=\left(Y_{q j}^{k p}\right) \quad(q=1,2, \cdots, P W F+W F(k) ; j=1,2, \cdots, W S(k) ; k=1,2, \cdots, S L)
\end{aligned}
$$


$y_{q j}^{k p}$, represents the controlling quantity of the pollutant into the river of pollutant $p$ of user $j$ in sub-region $k$, which was allocated from water function area $q$.

\subsubsection{Objective Function}

Based on the positive and negative effects generated by the links of "water supply-water use and consumption-drainage-pollutant carrying," the final objective function of macroscopic integrated optimal distribution of regional water consumption and pollutant-carrying capacity is the maximum net benefit in the process of integrated optimal distribution. Among them, as the intermediate product of the system, the benefits in the water supply link are utilized by the next link. In order to avoid repetition, it is not included in the final net benefit [22].

Therefore, the objective function can be expressed as the positive benefits in water use and consumption link, by deducting the negative effects in the drainage link and pollutant-carrying link, which is the net benefit of joint optimal allocation, which reaches its maximum. Through the emergy calculation methods of all the benefits mentioned above, the objective function of joint optimal allocation can be expressed as follows.

$$
F=\max \sum_{k=1}^{S L} \sum_{j=1}^{W S(k)} f_{j}^{k}=\max \left(\sum_{k=1}^{S L} \sum_{j=1}^{W S(k)} E_{U_{j}^{k}}(x)-\sum_{k=1}^{S L} \sum_{j=1}^{W S(k)} E_{D_{j}}^{k}(x)-\sum_{m=1}^{p} \sum_{k=1}^{S L} \sum_{j=1}^{W S(k)} E_{P}^{k p}(y)\right) .
$$

In this formula, $E_{U}$ represents the positive economic, social, and ecological benefits of water use and the consumption link in various water sectors, including the industrial water use benefits, agricultural water use benefits, domestic water use benefits, and ecological-environmental water use benefits. $E_{D}$ represents the negative environmental benefits in drainage link, which consists of the sewage treatment loss caused by industrial water and urban domestic water, and the water quality pollution loss caused by the direct discharge of agricultural drainage water and rural domestic sewage. $E_{P}$ represents the negative economic effects of the pollutant-carrying link, including the pollutant reduction costs in industrial water and urban domestic water.

According to the emergy evaluation methods, which have varying benefits, the concrete calculation measures are as follows.

$$
\left\{\begin{array}{lr}
f_{1}=E M_{p i}-E M_{i s}-E M_{i p} & (j=1, \text { represents the water - use department in industry }) \\
f_{2}=E M_{p a}-E M_{a d} & (j=2, \text { represents the water }- \text { use department in agriculture }) \\
f_{3}=E M_{l r}-E M_{d d}-E M_{d s}-E M_{d p} & (j=3, \text { represents the water - use department in life }) \\
f_{4}=E M_{d c}+E M_{c h}+E M_{c o}+E M_{s d} & (j=4, \text { represents the water - use department in ecological })
\end{array}\right\}
$$

In this formula, each symbol has the same meaning as above.

\subsubsection{Constraint Condition}

(1) Total water consumption constraint

Following the total quantity red line constraints from the development and utilization of water resources, regional water consumption should not exceed the control objective from the total regional water use.

$$
\sum_{k=1}^{S L} \sum_{i=1}^{P W Y+W Y(k)} \sum_{j=1}^{W S(k)} x_{i j}^{k} \leq T W .
$$

In this formula, $x_{i j}^{k}$ represents the amount of water of user $j$ in sub-region $k$, which was allocated from the water source $i$, and TW represents the control objective of the total regional water consumption.

(2) Available water resources constraint 
a. Public water supplies: The sum of the total water resources of each sector in the relevant sub-area, supplied by the public water supplies, is not more than the quantity of the available water resources for allocation.

$$
\sum_{k=1}^{S L} \sum_{j=1}^{W S(k)} x_{i j}^{k} \leq G Y W_{i}, \quad i \in P W Y .
$$

In this formula, $P W Y$ means the collection of public water supplies, and $G Y W_{i}$ represents the available water resources in the public water supplies.

b. Special water supplies: The total water resources of the relevant sector, supplied by special water supplies to sub-areas, does not exceed the amount of water resources available for allocation.

(1) Surface water sources

$$
\sum_{j=1}^{W S(k)} x_{i j}^{k} \leq W S_{i}^{k}, \quad i \in S W Y(k), k=1,2, \cdots, S L .
$$

(2) Groundwater sources

$$
\sum_{j=1}^{W S(k)} x_{i j}^{k} \leq W G_{i}^{k}+\Delta W_{i}^{k}, \quad i \in G W Y(k), k=1,2, \cdots, S L .
$$

In this formula, $W S_{i}^{k}$ and $W G_{i}^{k}$ represent the amount of water resources that are available for allocation in the $i$ special surface water and groundwater sources of sub-region $k$, respectively. $S W Y(k)$ and $G W Y(k)$ represent the collection of special surface water and groundwater sources of sub-region $\mathrm{k}$, and $\Delta W_{i}^{k}$ is the amount of over-exploited groundwater that is allowable in sub-region $k$.

(3) Water conveyance capacity constraint

The total amount of water from all the sources that are allocated for use by sector $j$ in sub-region $k$ cannot exceed the maximum carrying capacity of the water transfer project in use in sector $j$ from relevant sources.

$$
x_{i j}^{k} \leq Q_{i \max ,}^{k} \quad i \in P W Y \cup W Y(k), k=1,2, \cdots, S L .
$$

In this formula, $Q_{i}^{k} \max$ is the maximum carrying capacity from source $i$ to sub-region $k$ in water use sector $j$.

(4) Water use efficiency constraint

Following the red line of controlling over water use efficiency, the quota of the water requirement of industry, agriculture, and national economy should be less than the control index examined for water use efficiency.

$$
D_{i} \leq D_{i d}, D_{a} \leq D_{a d}, D_{e} \leq D_{e d}
$$

In this formula, $D_{i}, D_{a}$, and $D_{e}$ represent the quota of the water requirement for industries, agriculture, and the national economy, respectively. $D_{i d}, D_{a d}$, and $D_{e d}$ are the control indexes of water use efficiency for industries, agriculture, and the national economy, according to the red line of controlling water use efficiency, respectively.

(5) Pollutant carrying capacity of water function areas constraint 
Pollutant carrying capacity constraints of the water function area means the total pollutant carrying capacity of all the water use sectors cannot exceed the maximum amount of pollution that is allowed in the water function area.

$$
\sum_{k}^{S L} \sum_{j \in G N W S(q)} y_{q j}^{k p} \leq W_{q}^{p} .
$$

In this formula, $y_{q j}^{k p}$ represents the pollutant-carrying capacity of pollutant $p$ for user $j$ in sub-region $k$, allocated from the water function area $q$. GNWS $(q)$ represents all the water use sectors related to water function area $q$ in this region. $W_{q}^{p}$ represents the maximum amount of pollutant $p$ that is allowed in the water functional area $\mathrm{q}$, and other symbols have the same meaning as above.

(6) Mutual relation between water quantity and the pollution carrying capacity constraint

By using the pollutant-carrying capacity allocated to each water sector, the amount of pollutants discharged by pollutant discharging units and its allocated water amount are constrained. That is, the amount of pollutants discharge under a certain amount of allocated water conditions by each water sector in each sub-area, after the status quo treatment and subsequent reduction links, shows that the final pollutants discharge into the water body cannot exceed the controlled amount of pollutants into the river allocated to this water sector by the corresponding water functional area.

$$
x_{j}^{k} \leq \frac{y_{q j}^{k p}+\lambda_{q j}^{k p} \cdot c y_{q j}^{k p}}{\lambda_{q j}^{k p} \cdot \alpha_{j} \cdot\left[P C_{j}^{k p}-\eta_{j}^{k} \cdot\left(P C_{j}^{k p}-T P C_{j}^{k p}\right)\right]} .
$$

In this formula, $P C_{j}^{k p}$ is the concentration of the pollutant $p$ in the wastewater discharged by water use sector $j$ in sub-region $k . T P C_{j}^{k p}$ represents the concentration of the pollutant $p$ by processing in the wastewater discharged by the water used by sector $j$ in sub-area $k . c y_{q j}^{k p}$ represents the quantity of pollutant $p$ needed to be reduced in the sub-region $k$ water use sector $j$ before being discharged into water function area $q$, t. $\alpha_{j}$ is the sewage discharge rate of user $j . \eta_{j}^{k}$ is the treatment rate for wastewater of user $j$ in sub-area $k$, and $\lambda_{q j}^{k p}$ represents the coefficient in the river of pollutant $p$ discharged into the water function area $q$ by the sub-region $k$ of water use sector $j$. Other symbols have the same meaning as above.

(7) Pollutant reduction funding constraint

The investment scale of regional pollution control is affected by economic and social development and is limited to a certain period. The funds put into pollutant reduction measures should meet the funding constraints.

$$
S D C_{k} \leq S_{\max k}
$$

In this formula, $S_{\max k}$ represents the total amount of pollutant reduction funds in the corresponding period.

(8) Other constraints

Minimum water consumption constraints in various sectors (industrial, agricultural, domestic, and ecological water sectors) are specifically set according to regional characteristics.

(9) Variable non-negative constraint

The above objective functions and constraints constitute the joint optimal allocation model of regional water consumption and pollutant-carrying capacity. 


\section{Results}

3.1. The Construction of the Joint Optimal Allocation Model of Water Consumption and Pollutant-Carrying Capacity in Zhengzhou City

\subsubsection{The Sub-Area Division and Water Source and User Composition}

\section{(1) Sub-Area Division}

Based on «The comprehensive planning of water resources in Zhengzhou», Zhengzhou city is divided into seven sub-districts (SL = 7), as administrative districts, including Zhengzhou district, Dengfeng city, Xinzheng city, Xinmi city, Xingyang city, Gongyi city, and Zhongmou county.

(2) Water functional zoning

The main water functional areas in Zhengzhou are shown in Table 2.

Table 2. The water function zoning table in Zhengzhou.

\begin{tabular}{|c|c|c|c|}
\hline Name of Water Function Area & Sub-Area & River & Source of Pollutant \\
\hline The agricultural water area of Gongyi in Yiluo River & & $\begin{array}{l}\text { Yiluo } \\
\text { River }\end{array}$ & Rural domestic, Agriculture \\
\hline The sewage control area of Gongyi in Housi River & Gongyi city & $\begin{array}{l}\text { Housi } \\
\text { River }\end{array}$ & Industry, Domestic \\
\hline The sewage control area of Gongyi in Sishui River & & $\begin{array}{l}\text { Sishui } \\
\text { River }\end{array}$ & Industry, Agriculture \\
\hline The sewage control area of Xingyang in Suoxu River & Xingyang city & $\begin{array}{l}\text { Suoxu } \\
\text { River }\end{array}$ & Industry, Urban domestic \\
\hline The sewage control area of Xinzheng in Shuangji River & Xinzheng city & $\begin{array}{l}\text { Shuangji } \\
\text { River }\end{array}$ & Industry, Agriculture, Domestic \\
\hline $\begin{array}{l}\text { The industrial water area of Dengfeng in Ying River } \\
\text { The sewage control area of Dengfeng in Ying river }\end{array}$ & Dengfeng city & $\begin{array}{l}\text { Ying River } \\
\text { Ying River }\end{array}$ & $\begin{array}{c}\text { Industry } \\
\text { Domestic, Agriculture }\end{array}$ \\
\hline
\end{tabular}

(3) Water source and user classification

Combined with the actual situation and planning results of water resources in Zhengzhou, the common water sources include the yellow river water diversion and south-to-north water diversion, which can supply water to any subarea within the region during water distribution. Special water sources include the water storage project, water diversion project (excluding the yellow river water diversion), and groundwater by reclaiming water and rainwater. The water use sectors in each sub-district are divided into industrial water use, agricultural water use, urban domestic water use, rural domestic water use, and ecological environmental water use.

\subsubsection{Scene Settings of Joint Optimal Allocation}

In terms of the water supply source, water distribution engineering, water use sector, wastewater treatment, water function areas, and the engineering and non-engineering measures, which have influence over water distribution, pollutant-carrying capacity distribution, and water use efficiency, are comprehensively analyzed. In accordance with the principle of feasible technology and possible economic benefit, the joint optimal allocation scenes of water consumption and pollutant-carrying capacity are constructed. The scene mainly refers to the combination of different control measures that affect joint optimal allocation results in order to analyze the mutual restriction relationship between 
water quantity and pollution carrying capacity intuitively, so as to obtain the joint optimal allocation situations of different combinations. The scene settings mainly consider the aspects of water quantity, pollutant-carrying capacity, and integrated regulation.

(1) Water demand side: From the perspective of water saving measures, improving water use efficiency, and analyzing the influence of the amount of water in the joint optimal allocation.

(2) Sewage treatment side: Starting from the sewage treatment level, analyze the influence of current and advanced treatments on the results of the joint optimal allocation.

(3) Pollutant reduction funds side: From the perspective of pollutant reduction capital investment, analyze the limitation and influence of different capital investment levels on the water use structure of each sector.

On this basis, combined with the water conservation development planning and socio-economic development planning in Zhengzhou, the above regulation measures were combined in various ways. Then, the scene settings of the joint optimal allocation in Zhengzhou was constructed, and the configuration effects of different measures were compared, as shown in the Table 3.

Table 3. Scene settings of the joint optimal allocation in Zhengzhou city.

\begin{tabular}{|c|c|c|c|c|c|c|c|}
\hline \multirow{2}{*}{$\begin{array}{l}\text { Scene } \\
\text { Settings }\end{array}$} & \multirow{2}{*}{$\begin{array}{l}\text { Pollutant } \\
\text { Carrying } \\
\text { Capacity } \\
\text { Constraints }\end{array}$} & \multicolumn{2}{|c|}{ Water Demand Side } & \multicolumn{2}{|c|}{ Sewage Treatment Side } & \multicolumn{2}{|c|}{$\begin{array}{l}\text { Pollutant Reduction } \\
\text { Funds Side }\end{array}$} \\
\hline & & $\begin{array}{l}\text { Moderate } \\
\text { Water } \\
\text { Saving }\end{array}$ & $\begin{array}{l}\text { Strengthening } \\
\text { Water Saving }\end{array}$ & $\begin{array}{l}\text { Moderate } \\
\text { Treatment }\end{array}$ & $\begin{array}{c}\text { High } \\
\text { Treatment }\end{array}$ & $\begin{array}{l}\text { Current } \\
\text { Level }\end{array}$ & $\begin{array}{c}\text { Increasing } \\
\text { Investment }\end{array}$ \\
\hline Scene 1 & $\sqrt{ }$ & $\sqrt{ }$ & & $\sqrt{ }$ & & $\sqrt{ }$ & \\
\hline Scene 2 & $\sqrt{ }$ & $\sqrt{ }$ & & $\sqrt{ }$ & & & $\sqrt{ }$ \\
\hline Scene 3 & $\sqrt{ }$ & $\sqrt{ }$ & & & $\sqrt{ }$ & $\sqrt{ }$ & \\
\hline Scene 4 & $\sqrt{ }$ & $\sqrt{ }$ & & & $\sqrt{ }$ & & $\sqrt{ }$ \\
\hline Scene 5 & $\sqrt{ }$ & & $\sqrt{ }$ & $\sqrt{ }$ & & $\sqrt{ }$ & \\
\hline Scene 6 & $\sqrt{ }$ & & $\sqrt{ }$ & $\sqrt{ }$ & & & $\sqrt{ }$ \\
\hline Scene 7 & $\sqrt{ }$ & & $\sqrt{ }$ & & $\sqrt{ }$ & $\sqrt{ }$ & \\
\hline Scene 8 & $\sqrt{ }$ & & $\sqrt{ }$ & & $\sqrt{ }$ & & $\sqrt{ }$ \\
\hline
\end{tabular}

3.2. The Results of Joint Optimal Allocation of Water Consumption and Pollutant Carrying Capacity in Zhengzhou City

\subsubsection{The Prediction of Water Supply and Demand of Zhengzhou in 2030}

According to the actual situation of Zhengzhou city, the moderate water-saving and intensified water-saving scenes are put forward in 2030. Referring to the water resources evaluation and other planning achievements of Zhengzhou, the water demand prediction results in 2030 are shown in Tables 4 and 5, and the available water supply prediction result of Zhengzhou in 2030 is shown in Table 6.

\subsubsection{Calculation of the Emergy Parameters of Water Resources}

Combined with the basic data of water resources, economy, society, and ecology in «the statistical yearbook of Zhengzhou city» and «The water resources bulletin of Zhengzhou city», the emergy parameters involved in joint optimal allocation process are calculated by the emergy calculation method, which mainly include emergy transformity of different water bodies and emergy parameters of water sectors. With regard to the reference value for planning annual emergy parameters, the results are shown in Tables 7-12. 
Table 4. The water demand prediction results under a moderate water-saving scene. (Unit: $10^{4} \mathrm{~m}^{3}$ ).

\begin{tabular}{|c|c|c|c|c|c|c|c|c|c|c|c|c|}
\hline \multirow{2}{*}{ Sub-Area } & \multirow{2}{*}{$\begin{array}{c}\text { Industrial Water } \\
\text { Demand }\end{array}$} & \multicolumn{3}{|c|}{ Agricultural Water Demand } & \multicolumn{2}{|c|}{$\begin{array}{c}\text { Domestic Water } \\
\text { Demand }\end{array}$} & \multicolumn{3}{|c|}{ Ecological Water Demand } & \multicolumn{3}{|c|}{ Total } \\
\hline & & $P=50 \%$ & $P=75 \%$ & $P=95 \%$ & Urban & Rural & $P=50 \%$ & $P=75 \%$ & $P=95 \%$ & $P=50 \%$ & $P=75 \%$ & $P=95 \%$ \\
\hline Gongyi city & 16,531 & 3389 & 3707 & 4029 & 3843 & 1586 & 74 & 81 & 84 & 25,423 & 25,748 & 26,073 \\
\hline Dengfeng city & 7486 & 1894 & 1973 & 2032 & 2267 & 1305 & 101 & 106 & 110 & 13,053 & 13,137 & 13,200 \\
\hline Xingyang city & 8701 & 12,059 & 12,841 & 13,137 & 2223 & 1592 & 100 & 107 & 110 & 24,675 & 25,464 & 25,763 \\
\hline Xinmi city & 9022 & 2742 & 2863 & 3047 & 3267 & 1570 & 86 & 93 & 96 & 16,687 & 16,815 & 17,002 \\
\hline Zhengzhou district & 14,300 & 13,545 & 13,968 & 14,354 & 42,870 & 4173 & 31,277 & 32,215 & 33,826 & 106,165 & 107,526 & 109,523 \\
\hline Xinzheng city & 8293 & 3770 & 4074 & 4254 & 2732 & 780 & 321 & 332 & 358 & 15,896 & 16,211 & 16,417 \\
\hline Zhongmou county & 4347 & 31,995 & 34,984 & 35,892 & 2650 & 1677 & 434 & 469 & 488 & 41,103 & 44,127 & 45,054 \\
\hline The whole city & 69,301 & 69,394 & 74,410 & 76,745 & 59,852 & 12,683 & 32,393 & 33,403 & 35,072 & 243,623 & 249,649 & 253,653 \\
\hline
\end{tabular}

Table 5. The water demand prediction results under an intensified water-saving scene. (Unit: $10^{4} \mathrm{~m}^{3}$ ).

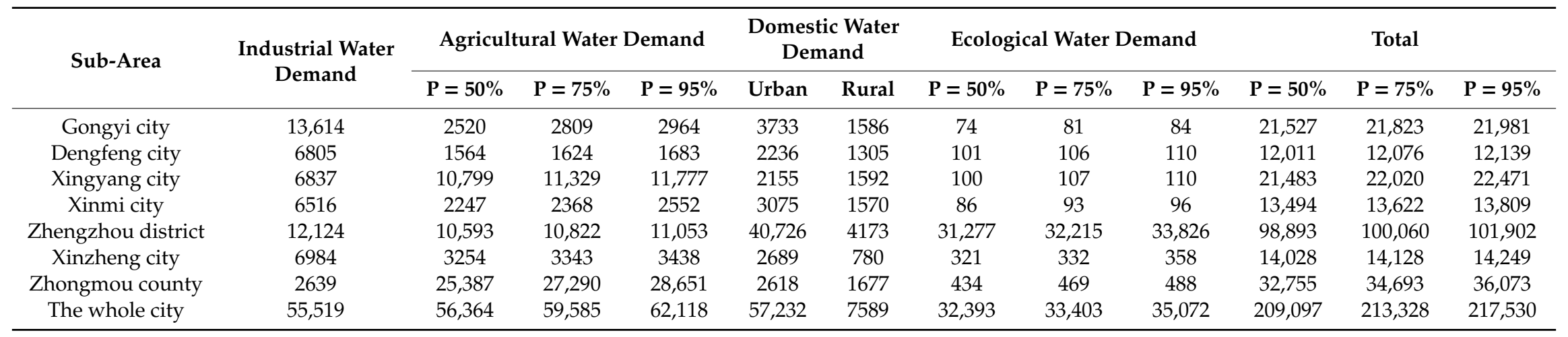


Table 6. The available water supply prediction results of Zhengzhou in 2030. (Unit: $10^{4} \mathrm{~m}^{3}$ ).

\begin{tabular}{|c|c|c|c|c|c|c|c|c|c|c|c|c|c|}
\hline \multirow{4}{*}{ Sub-Area } & \multicolumn{11}{|c|}{ Special Water Source } & \multicolumn{2}{|c|}{ Common Water Source } \\
\hline & \multicolumn{3}{|c|}{ Surface Water } & \multirow{3}{*}{ Groundwater } & \multicolumn{4}{|c|}{ Unconventional Water Source } & \multicolumn{3}{|c|}{ Total } & \multirow{3}{*}{$\begin{array}{c}\text { Yellow } \\
\text { River Water } \\
\text { Diversion }\end{array}$} & \multirow{3}{*}{$\begin{array}{c}\text { South-to-North } \\
\text { Water } \\
\text { Diversion }\end{array}$} \\
\hline & \multirow{2}{*}{$50 \%$} & \multirow{2}{*}{$75 \%$} & \multirow{2}{*}{$95 \%$} & & \multicolumn{3}{|c|}{ Rainwater Collection } & \multirow{2}{*}{$\begin{array}{l}\text { Reclaimed } \\
\text { Water }\end{array}$} & \multirow{2}{*}{$50 \%$} & \multirow{2}{*}{$75 \%$} & \multirow{2}{*}{$95 \%$} & & \\
\hline & & & & & $50 \%$ & $75 \%$ & $95 \%$ & & & & & & \\
\hline Gongyi city & 10,030 & 9848 & 9550 & 7204 & 292 & 271 & 245 & 6990 & 24,516 & 24,313 & 23,989 & & \\
\hline Dengfeng city & 3823 & 3209 & 2269 & 5801 & 252 & 238 & 221 & 4357 & 14,233 & 13,605 & 12,648 & & \\
\hline Xingyang city & 12,094 & 11,832 & 11,506 & 5880 & 260 & 250 & 238 & 4661 & 22,895 & 22,623 & 22,285 & & \\
\hline Xinmi city & 2988 & 2641 & 2079 & 6759 & 193 & 177 & 158 & 4059 & 13,999 & 13,636 & 13,055 & & \\
\hline Zhengzhou district & 111,760 & 111,369 & 11,0992 & 8333 & 931 & 779 & 591 & 8096 & 129,120 & 128,577 & 128,012 & & \\
\hline Xinzheng city & 11,474 & 11,216 & 10,716 & 5545 & 105 & 94 & 80 & 4234 & 21,358 & 21,089 & 20,575 & & \\
\hline Zhongmou county & 21,419 & 21,419 & 21,419 & 16,873 & 34 & 27 & 20 & 19,510 & 57,836 & 57,829 & 57,822 & & \\
\hline The whole city & 173,588 & 171,534 & 168,531 & 56,394 & 2066 & 1836 & 1552 & 51,907 & 283,955 & 281,671 & 278,384 & 42,000 & 54,000 \\
\hline
\end{tabular}

Table 7. The emergy parameters of industrial water sector in Zhengzhou.

\begin{tabular}{|c|c|c|c|c|c|c|c|}
\hline Project & $\begin{array}{c}\text { Zhengzhou } \\
\text { District }\end{array}$ & $\begin{array}{l}\text { Zhongmou } \\
\text { County }\end{array}$ & Gongyi City & Xingyang City & Xinmi City & $\begin{array}{c}\text { Xinzheng } \\
\text { City }\end{array}$ & $\begin{array}{c}\text { Dengfeng } \\
\text { City }\end{array}$ \\
\hline The emergy of industrial water $\left(10^{20} \mathrm{sej}\right)$ & 7.49 & 2.42 & 5.08 & 4.86 & 4.59 & 46.21 & 3.71 \\
\hline Total emergy input of industrial production $\left(10^{20} \mathrm{sej}\right)$ & 268.2 & 54.9 & 209.9 & 101.6 & 143.6 & 101.4 & 225.6 \\
\hline Total emergy output of industrial production $\left(10^{20} \mathrm{sej}\right)$ & 685.8 & 104.8 & 558.4 & 247.4 & 372.2 & 160.5 & 610.9 \\
\hline Emergy contribution rate of industrial water (\%) & 2.79 & 4.40 & 2.42 & 4.78 & 3.20 & 4.56 & 1.65 \\
\hline Emergy contribution amount of industrial water $\left(10^{20} \mathrm{sej}\right)$ & 19.1 & 4.61 & 13.5 & 11.83 & 11.91 & 7.31 & 10.08 \\
\hline Monetary value of industrial water $\left(10^{8} ¥\right)$ & 66.75 & 16.08 & 47.14 & 41.25 & 41.55 & 25.52 & 35.16 \\
\hline Emergy benefit of per $\mathrm{m}^{3}$ industrial water $\left(10^{12} \mathrm{sej} / \mathrm{m}^{3}\right)$ & 15.13 & 11.16 & 15.04 & 14.30 & 15.21 & 9.31 & 15.35 \\
\hline Monetary benefit of per $\mathrm{m}^{3}$ industrial water $\left(¥ / \mathrm{m}^{3}\right)$ & 52.80 & 38.93 & 52.47 & 49.89 & 53.07 & 32.49 & 53.56 \\
\hline
\end{tabular}


Table 8. The emergy parameters of agricultural water sector in Zhengzhou.

\begin{tabular}{|c|c|c|c|c|c|c|c|}
\hline Project & $\begin{array}{c}\text { Zhengzhou } \\
\text { District }\end{array}$ & $\begin{array}{l}\text { Zhongmou } \\
\text { County }\end{array}$ & Gongyi City & Xingyang City & Xinmi City & $\begin{array}{c}\text { Xinzheng } \\
\text { City }\end{array}$ & $\begin{array}{c}\text { Dengfeng } \\
\text { City }\end{array}$ \\
\hline The emergy of agricultural water $\left(10^{20} \mathrm{sej}\right)$ & 0.08 & 2.88 & 0.20 & 0.56 & 0.25 & 0.61 & 0.16 \\
\hline Total emergy input of agricultural production $\left(10^{20} \mathrm{sej}\right)$ & 10.4 & 16.6 & 13.5 & 9.49 & 9.01 & 10.63 & 8.50 \\
\hline Total emergy output of agricultural production $\left(10^{20} \mathrm{sej}\right)$ & 26.6 & 78.1 & 39.8 & 187.1 & 62.3 & 61.9 & 15.5 \\
\hline Emergy contribution rate of agricultural water (\%) & 8.44 & 17.38 & 1.50 & 5.95 & 2.76 & 5.71 & 1.93 \\
\hline Emergy contribution amount of agricultural water $\left(10^{20}\right.$ sej $)$ & 2.25 & 13.6 & 0.60 & 11.13 & 1.72 & 3.54 & 0.30 \\
\hline Monetary value of agricultural water $\left(10^{8} ¥\right)$ & 7.84 & 47.36 & 2.08 & 38.83 & 6.00 & 12.34 & 1.05 \\
\hline Emergy benefit per $\mathrm{m}^{3}$ agricultural water $\left(10^{12} \mathrm{sej} / \mathrm{m}^{3}\right)$ & 3.60 & 6.21 & 3.21 & 26.51 & 9.27 & 7.92 & 1.99 \\
\hline Monetary benefit per $\mathrm{m}^{3}$ agricultural water $\left(¥ / \mathrm{m}^{3}\right)$ & 12.55 & 21.65 & 11.18 & 92.47 & 32.36 & 27.61 & 6.97 \\
\hline
\end{tabular}

Table 9. The emergy parameters of the urban domestic water sector in Zhengzhou.

\begin{tabular}{|c|c|c|c|c|c|c|c|}
\hline Project & $\begin{array}{l}\text { Zhengzhou } \\
\text { District }\end{array}$ & $\begin{array}{l}\text { Zhongmou } \\
\text { County }\end{array}$ & Gongyi City & Xingyang City & Xinmi City & $\begin{array}{l}\text { Xinzheng } \\
\text { City }\end{array}$ & $\begin{array}{c}\text { Dengfeng } \\
\text { City }\end{array}$ \\
\hline Emergy contribution rate of urban domestic water (\%) & 42.24 & 49.44 & 63.72 & 47.43 & 46.40 & 48.26 & 57.42 \\
\hline Engel coefficient (\%) & 37.40 & 29.90 & 33.10 & 31.70 & 25.90 & 28.20 & 30.50 \\
\hline Disposable income of urban residents $(¥ / p)$ & 22,477 & 16,588 & 18,186 & 18,188 & 18,194 & 18,204 & 17,565 \\
\hline Emergy value of urban domestic water $\left(10^{14} \mathrm{sej} / \mathrm{p}\right)$ & 10.18 & 7.03 & 11.00 & 7.84 & 6.27 & 7.10 & 8.82 \\
\hline Monetary value of urban domestic water $(¥ / p)$ & 3550.86 & 2452.13 & 3835.67 & 2734.62 & 2186.48 & 2477.44 & 3076.18 \\
\hline Urban domestic water amount per person per year $\left(\mathrm{m}^{3} / \mathrm{p}\right)$ & 42.07 & 40.67 & 34.20 & 33.03 & 35.39 & 48.04 & 21.01 \\
\hline Emergy benefit per $\mathrm{m}^{3}$ urban domestic water $\left(10^{12} \mathrm{sej} / \mathrm{m}^{3}\right)$ & 24.20 & 17.29 & 32.16 & 23.74 & 17.72 & 14.78 & 41.98 \\
\hline Monetary benefit per $\mathrm{m}^{3}$ urban domestic water $\left(¥ / \mathrm{m}^{3}\right)$ & 84.40 & 60.29 & 112.15 & 82.79 & 61.78 & 51.57 & 146.42 \\
\hline
\end{tabular}


Table 10. The emergy parameters of the rural domestic water sector in Zhengzhou.

\begin{tabular}{|c|c|c|c|c|c|c|c|}
\hline Project & $\begin{array}{l}\text { Zhengzhou } \\
\text { District }\end{array}$ & $\begin{array}{l}\text { Zhongmou } \\
\text { County }\end{array}$ & Gongyi City & Xingyang City & Xinmi City & $\begin{array}{c}\text { Xinzheng } \\
\text { City }\end{array}$ & $\begin{array}{c}\text { Dengfeng } \\
\text { City }\end{array}$ \\
\hline Emergy contribution rate of rural domestic water (\%) & 31.83 & 26.10 & 28.20 & 30.07 & 19.81 & 21.30 & 25.88 \\
\hline Engel coefficient $(\%)$ & 37.40 & 29.90 & 33.10 & 31.70 & 25.90 & 28.20 & 30.50 \\
\hline Disposable income of rural residents ( $¥ / p)$ & 13,522 & 10,216 & 11,392 & 10,846 & 10,835 & 11,344 & 9788 \\
\hline Emergy value of rural domestic water $\left(10^{14} \mathrm{sej} / \mathrm{p}\right)$ & 4.62 & 2.29 & 3.05 & 2.96 & 1.59 & 1.95 & 2.21 \\
\hline Monetary value of rural domestic water $(¥ / p)$ & 1609.81 & 797.25 & 1063.39 & 1033.89 & 555.92 & 681.39 & 772.62 \\
\hline Rural domestic water amount per person per year $\left(\mathrm{m}^{3} / \mathrm{p}\right)$ & 42.07 & 40.67 & 34.20 & 33.03 & 35.39 & 48.04 & 21.01 \\
\hline Emergy benefit per $\mathrm{m}^{3}$ rural domestic water $\left(10^{12} \mathrm{sej} / \mathrm{m}^{3}\right)$ & 10.98 & 5.63 & 8.92 & 8.96 & 4.49 & 4.06 & 10.52 \\
\hline Monetary benefit per $\mathrm{m}^{3}$ rural domestic water $\left(¥ / \mathrm{m}^{3}\right)$ & 38.27 & 19.60 & 31.09 & 31.30 & 15.71 & 14.18 & 36.77 \\
\hline
\end{tabular}

Table 11. The emergy parameters of the ecological water sector in Zhengzhou.

\begin{tabular}{|c|c|c|c|c|c|c|c|}
\hline Project & $\begin{array}{c}\text { Zhengzhou } \\
\text { District }\end{array}$ & $\begin{array}{l}\text { Zhongmou } \\
\text { County }\end{array}$ & Gongyi City & Xingyang City & Xinmi City & $\begin{array}{l}\text { Xinzheng } \\
\text { City }\end{array}$ & $\begin{array}{l}\text { Dengfeng } \\
\text { City }\end{array}$ \\
\hline Average annual temperature $\left({ }^{\circ} \mathrm{C}\right)$ & 13.7 & 13.7 & 13.7 & 13.7 & 13.7 & 13.7 & 13.7 \\
\hline Latent heat of evaporation $(\mathrm{J} / \mathrm{g})$ & 2475.0 & 2475.0 & 2475.0 & 2475.0 & 2475.0 & 2475.0 & 2475.0 \\
\hline Evaporation deep (mm) & 620.00 & 621.00 & 622.00 & 623.00 & 624.00 & 625.00 & 626.00 \\
\hline Annual evaporation $\left(10^{15} \mathrm{~m}^{3}\right)$ & 0.62 & 0.87 & 0.65 & 0.59 & 0.61 & 0.55 & 0.76 \\
\hline Evaporation energy $\left(10^{19} \mathrm{~J}\right)$ & 0.15 & 0.22 & 0.16 & 0.15 & 0.15 & 0.14 & 0.19 \\
\hline Emergy transformity of steam (sej/J) & 13.20 & 14.20 & 15.20 & 16.20 & 17.20 & 18.20 & 19.20 \\
\hline Evaporation emergy $\left(10^{20} \mathrm{sej}\right)$ & 0.20 & 0.31 & 0.24 & 0.24 & 0.26 & 0.25 & 0.36 \\
\hline Ecological water consumption $\left(10^{8} \mathrm{~m}^{3}\right)$ & 0.71 & 0.82 & 1.40 & 0.61 & 0.69 & 0.59 & 1.72 \\
\hline Emergy benefit per $\mathrm{m}^{3}$ ecological water $\left(10^{12} \mathrm{sej} / \mathrm{m}^{3}\right)$ & 0.28 & 0.38 & 0.17 & 0.39 & 0.37 & 0.42 & 0.21 \\
\hline Monetary benefit per $\mathrm{m}^{3}$ ecological water $\left(¥ / \mathrm{m}^{3}\right)$ & 0.10 & 0.13 & 0.06 & 0.14 & 0.13 & 0.15 & 0.07 \\
\hline
\end{tabular}


Table 12. The emergy transformity of different water bodies in Zhengzhou.

\begin{tabular}{|c|c|c|c|c|c|c|c|}
\hline Project & $\begin{array}{c}\text { Zhengzhou } \\
\text { District }\end{array}$ & $\begin{array}{c}\text { Zhongmou } \\
\text { County }\end{array}$ & Gongyi City & Xingyang City & Xinmi City & $\begin{array}{l}\text { Xinzheng } \\
\text { City }\end{array}$ & $\begin{array}{l}\text { Dengfeng } \\
\text { City }\end{array}$ \\
\hline Emergy transformity of surface water $\left(10^{11} \mathrm{sej} / \mathrm{m}^{3}\right)$ & 8.10 & 8.10 & 4.07 & 8.79 & 8.23 & 8.59 & 3.91 \\
\hline Emergy transformity of groundwater $\left(10^{12} \mathrm{sej} / \mathrm{m}^{3}\right)$ & 1.44 & 1.26 & 1.20 & 1.25 & 1.30 & 1.29 & 1.23 \\
\hline water diversion cost $\left(¥ / \mathrm{m}^{3}\right)$ & 0.29 & 0.29 & 0.29 & 0.29 & 0.29 & 0.29 & 0.29 \\
\hline Reservoir construction cost $\left(¥ / \mathrm{m}^{3}\right)$ & 1.14 & 1.14 & 1.14 & 1.14 & 1.14 & 1.14 & 1.14 \\
\hline Tube Wells pumping station construction cost $\left(¥ / \mathrm{m}^{3}\right)$ & 0.24 & 0.24 & 0.24 & 0.24 & 0.24 & 0.24 & 0.24 \\
\hline Water conservancy project cost of yellow river $\left(¥ / \mathrm{m}^{3}\right)$ & 0.59 & 0.59 & 0.59 & 0.59 & 0.59 & 0.59 & 0.59 \\
\hline $\begin{array}{l}\text { Emergy transformity of surface water after engineering } \\
\text { consideration }\left(10^{12} \mathrm{sej} / \mathrm{m}^{3}\right)\end{array}$ & 1.22 & 1.22 & 0.82 & 1.29 & 1.23 & 1.27 & 0.80 \\
\hline $\begin{array}{l}\text { Emergy transformity of groundwater after engineering } \\
\text { consideration }\left(10^{12} \mathrm{sej} / \mathrm{m}^{3}\right)\end{array}$ & 1.60 & 1.42 & 1.36 & 1.40 & 1.45 & 1.45 & 1.38 \\
\hline $\begin{array}{c}\text { Emergy transformity of yellow river after engineering } \\
\text { consideration }\left(10^{11} \mathrm{sej} / \mathrm{m}^{3}\right)\end{array}$ & 1.69 & 1.69 & 1.69 & 1.69 & 1.69 & 1.69 & 1.69 \\
\hline
\end{tabular}




\subsubsection{Calculation of the Pollutant Carrying Capacity Parameters of the Water Function Area}

According to the water quality objectives determined in «The comprehensive planning of water resources in Zhengzhou city», and combined with the comprehensive hydrological conditions and attenuation coefficient of Zhengzhou, $\mathrm{COD}$ and $\mathrm{NH}_{3}-\mathrm{N}$ are determined to be the key factors for the pollutant carrying capacity calculation. The calculation results of Zhengzhou in 2030 are shown in Table 13.

Table 13. The pollutant carrying capacity parameters of the main water function area. (Unit: $t / a)$.

\begin{tabular}{llcc}
\hline \multicolumn{1}{c}{ Sub-Area } & \multicolumn{1}{c}{ Water Function Area } & COD & $\mathbf{N H}_{3}-\mathbf{N}$ \\
\hline \multirow{2}{*}{ Zhengzhou district } & The sewage control area of Zhengzhou in Jialu River & 4052.1 & 344.4 \\
& The sewage control area of Zhengzhou in Qili River & 5287.1 & 228.3 \\
\hline \multirow{2}{*}{ Zhongmou county } & The sewage control area of Zhongmou in Jialu River & 2376.1 & 117.9 \\
& The agricultural water area of Zhongmou in Jialu River & 512.9 & 13.1 \\
\hline \multirow{2}{*}{ Gongyicity } & The agricultural water area of Gongyi in Yiluo River & 686.3 & 39 \\
& The sewage control area of Gongyi in Housi River & 1893.4 & 186.3 \\
\hline \multirow{2}{*}{ Xingyang city } & The sewage control area of Gongyi in Sishui River & 1431.1 & 75.4 \\
& The sewage control area of Xingyang in Suoxu River & 2235.8 & 139.2 \\
\hline \multirow{2}{*}{ Xinmi city } & The sewage control area of Xinmi in Shuangji River & 2613 & 158.9 \\
\hline Xinzheng city & The sewage control area of Xinzheng in Shuangii River & 1406.6 & 66.3 \\
\hline \multirow{2}{*}{ Dengfeng city } & The industrial water area of Dengfeng in Ying River & 625.9 & 34.3 \\
& The sewage control area of Dengfeng in Ying River & 1072.4 & 111.8 \\
\hline Total & & $23,997.2$ & 1479.4 \\
\hline
\end{tabular}

On this basis, combining with the statistical data of sewage treatment quantity, treatment cost and total investment of the sewage treatment project in Zhengzhou city, the unit sewage treatment costs of Zhengzhou are determined: the industrial wastewater treatment cost is 0.914 yuan/ton, and the urban domestic sewage treatment cost is 0.528 yuan/ton. Then, using the emergy calculation method of water resources eco-economic system in literature [9], the emergy transformity of water bodies before and after pollution in Zhengzhou are $6.26 \times 10^{11} \mathrm{sej} / \mathrm{m}$ and $8.05 \times 10^{12} \mathrm{sej} / \mathrm{m}$, respectively.

\subsubsection{The Integrated Optimal Distribution Results of Zhengzhou in 2030}

Using the solution methods established above, the joint optimal allocation models under different scenes are solved, and the results of joint optimal allocation of water consumption and pollutant carrying capacity in Zhengzhou city are obtained. The joint optimal allocation result under each scene is called a scheme. Then, the detailed results of the joint optimal allocation under the $50 \%$ guarantee rate of Zhengzhou city in 2030 are analyzed, as shown in Table 14. 
Table 14. The integrated optimal distribution results of Zhengzhou in 2030 ( $p=50 \%$ ).

\begin{tabular}{|c|c|c|c|c|c|c|c|c|c|c|c|c|}
\hline \multirow[t]{2}{*}{ Scheme } & \multirow[t]{2}{*}{ Water Use Sector } & \multirow[t]{2}{*}{$\begin{array}{l}\text { Quantity } \\
\text { of Water } \\
\text { Demand } \\
\left(10^{4} \mathrm{~m}^{3}\right)\end{array}$} & \multirow[t]{2}{*}{$\begin{array}{c}\text { Quantity of } \\
\text { Water } \\
\text { Distribution } \\
\left(10^{4} \mathrm{~m}^{3}\right)\end{array}$} & \multirow[t]{2}{*}{$\begin{array}{r}\text { Quantity } \\
\text { of Water } \\
\text { Shortage } \\
\left(10^{4} \mathrm{~m}^{3}\right)\end{array}$} & \multicolumn{2}{|c|}{$\begin{array}{c}\text { Pollutant } \\
\text { Discharge before } \\
\text { Pollutant Carrying } \\
\text { Link } \\
\text { (t) }\end{array}$} & \multicolumn{2}{|c|}{$\begin{array}{c}\text { Pollutant } \\
\text { Reduction in } \\
\text { Pollutant Carrying } \\
\text { Link } \\
\text { (t) }\end{array}$} & \multicolumn{2}{|c|}{$\begin{array}{l}\text { Pollutant in the } \\
\text { River after a } \\
\text { Pollution Carrying } \\
\text { Link } \\
\text { (t) }\end{array}$} & \multicolumn{2}{|c|}{$\begin{array}{c}\text { Distribution of } \\
\text { Pollution Carrying } \\
\text { Capacity } \\
\text { (t) }\end{array}$} \\
\hline & & & & & COD & $\mathrm{NH}_{3}-\mathrm{N}$ & COD & $\mathrm{NH}_{3}-\mathrm{N}$ & COD & $\mathrm{NH}_{3}-\mathrm{N}$ & COD & $\mathrm{NH}_{3}-\mathrm{N}$ \\
\hline \multirow{6}{*}{ Scheme 1} & Industrial & 90,109 & 78,235 & 11,874 & $27,351.3$ & 5702.2 & $10,247.6$ & 4680.1 & $17,103.7$ & 1022.1 & $17,103.7$ & 1022.1 \\
\hline & Urban domestic & 50,245 & 50,245 & 0 & 3901.1 & 305 & 1461.6 & 250.3 & 2439.5 & 54.7 & 2439.5 & 54.7 \\
\hline & Rural domestic & 8093 & 8093 & 0 & 803.1 & 181.4 & 300.9 & 148.9 & 502.2 & 32.5 & 502.2 & 32.5 \\
\hline & Agricultural & 48,489 & 37,908 & 10,581 & 6319.5 & 2064.9 & 2367.7 & 1694.8 & 3951.8 & 370.1 & 3951.8 & 370.1 \\
\hline & $\begin{array}{l}\text { Ecological } \\
\text { environment }\end{array}$ & 31,357 & 31,357 & 0 & 0 & 0 & 0 & 0 & 0 & 0 & 0 & 0 \\
\hline & Total & 228,294 & 205,837 & 22,456 & $38,374.9$ & 7799.3 & $14,377.7$ & 6319.9 & $23,997.2$ & 1479.4 & $23,997.2$ & 1479.4 \\
\hline \multirow{6}{*}{ Scheme 2} & Industrial & 90,109 & 79,470 & 10,639 & $27,792.1$ & 5558.4 & $11,304.6$ & 4799.9 & $16,487.5$ & 758.5 & $17,109.7$ & 1022.7 \\
\hline & Urban domestic & 50,245 & 50,245 & 0 & 3964.3 & 297.3 & 1612.4 & 256.7 & 2351.9 & 40.6 & 2440.5 & 54.7 \\
\hline & Rural domestic & 8093 & 8093 & 0 & 820.3 & 177.7 & 333.7 & 153.4 & 486.6 & 24.3 & 505 & 32.7 \\
\hline & Agricultural & 48,489 & 38,983 & 9506 & 6403.1 & 2007.1 & 2604.4 & 1733.2 & 3798.7 & 273.9 & 3941.9 & 369.3 \\
\hline & $\begin{array}{c}\text { Ecological } \\
\text { environment }\end{array}$ & 31,357 & 31,357 & 0 & 0 & 0 & 0 & 0 & 0 & 0 & 0 & 0 \\
\hline & Total & 228,294 & 208,148 & 20,146 & 38,980 & 8040.6 & 15855.1 & 6943.2 & 23124.9 & 1097.4 & $23,997.2$ & 1479.4 \\
\hline \multirow{6}{*}{ Scheme 3} & Industrial & 90,109 & 80,043 & 10,066 & 26,714 & 5342.8 & 9827.9 & 4411.5 & $16,886.1$ & 931.3 & $17,068.7$ & 1013.3 \\
\hline & Urban domestic & 50,245 & 50,245 & 0 & 3610.6 & 270.8 & 1328.3 & 223.6 & 2282.3 & 47.2 & 2307 & 51.4 \\
\hline & Rural domestic & 8093 & 8093 & 0 & 829.9 & 179.8 & 305.4 & 148.5 & 524.5 & 31.3 & 530.3 & 34.1 \\
\hline & Agricultural & 48,489 & 39,174 & 9315 & 6434.5 & 2016.9 & 2355.7 & 1657.3 & 4078.8 & 359.6 & 4091.2 & 380.7 \\
\hline & $\begin{array}{c}\text { Ecological } \\
\text { environment }\end{array}$ & 31,357 & 31,357 & 0 & 0 & 0 & 0 & 0 & 0 & 0 & 0 & 0 \\
\hline & Total & 228,294 & 20,8912 & 19,382 & 37,589 & 7810.3 & $13,817.2$ & 6440.8 & 23771.8 & 1369.5 & $23,997.2$ & 1479.4 \\
\hline \multirow{6}{*}{ Scheme 4} & Industrial & 90,109 & 80,195 & 9914 & $26,738.8$ & 5347.8 & $10,824.6$ & 4851 & 15914.2 & 496.8 & $17,067.4$ & 1013.6 \\
\hline & Urban domestic & 50,245 & 50,245 & 0 & 3620.4 & 270.8 & 1465.6 & 245.7 & 2154.8 & 25.1 & 2310.9 & 51.3 \\
\hline & Rural domestic & 8093 & 8093 & 0 & 833.2 & 179.8 & 337.3 & 163.1 & 495.9 & 16.7 & 531.8 & 34.1 \\
\hline & Agricultural & 48,489 & 38,852 & 9637 & 6403.1 & 2007.1 & 2592.2 & 1820.7 & 3810.9 & 186.4 & 4087.1 & 380.4 \\
\hline & $\begin{array}{c}\text { Ecological } \\
\text { environment }\end{array}$ & 31,357 & 31,357 & 0 & 0 & 0 & 0 & 0 & 0 & 0 & 0 & 0 \\
\hline & Total & 228,294 & 208,742 & 19,552 & 37,595 & 7805.5 & $15,219.7$ & 7080.4 & $22,375.3$ & 725.1 & $23,997.2$ & 1479.4 \\
\hline
\end{tabular}


Table 14. Cont.

\begin{tabular}{|c|c|c|c|c|c|c|c|c|c|c|c|c|}
\hline \multirow[t]{2}{*}{ Scheme } & \multirow[t]{2}{*}{ Water Use Sector } & \multirow[t]{2}{*}{$\begin{array}{l}\text { Quantity } \\
\text { of Water } \\
\text { Demand } \\
\left(10^{4} \mathrm{~m}^{3}\right)\end{array}$} & \multirow[t]{2}{*}{$\begin{array}{c}\text { Quantity of } \\
\text { Water } \\
\text { Distribution } \\
\left(10^{4} \mathrm{~m}^{3}\right)\end{array}$} & \multirow[t]{2}{*}{$\begin{array}{r}\text { Quantity } \\
\text { of Water } \\
\text { Shortage } \\
\left(10^{4} \mathrm{~m}^{3}\right)\end{array}$} & \multicolumn{2}{|c|}{$\begin{array}{c}\text { Pollutant } \\
\text { Discharge before } \\
\text { Pollutant Carrying } \\
\text { Link } \\
\text { (t) }\end{array}$} & \multicolumn{2}{|c|}{$\begin{array}{c}\text { Pollutant } \\
\text { Reduction in } \\
\text { Pollutant Carrying } \\
\text { Link } \\
\text { (t) }\end{array}$} & \multicolumn{2}{|c|}{$\begin{array}{l}\text { Pollutant in the } \\
\text { River after a } \\
\text { Pollution Carrying } \\
\text { Link } \\
\text { (t) }\end{array}$} & \multicolumn{2}{|c|}{$\begin{array}{c}\text { Distribution of } \\
\text { Pollution Carrying } \\
\text { Capacity } \\
\text { (t) }\end{array}$} \\
\hline & & & & & COD & $\mathrm{NH}_{3}-\mathrm{N}$ & COD & $\mathrm{NH}_{3}-\mathrm{N}$ & COD & $\mathrm{NH}_{3}-\mathrm{N}$ & COD & $\mathrm{NH}_{3}-\mathbf{N}$ \\
\hline \multirow{6}{*}{ Scheme 5} & Industrial & 77,733 & 76,120 & 1613 & $26,973.4$ & 5462.2 & $10,001.9$ & 4450.2 & $16,971.5$ & 1012 & $16,971.5$ & 1012 \\
\hline & Urban domestic & 48,815 & 48,815 & 0 & 3889.6 & 295.3 & 1442.3 & 240.6 & 2447.3 & 54.7 & 2447.3 & 54.7 \\
\hline & Rural domestic & 8093 & 8093 & 0 & 836.3 & 183.5 & 310.1 & 149.5 & 526.2 & 34 & 526.2 & 34 \\
\hline & Agricultural & 43,745 & 43,500 & 245 & 6440.3 & 2044 & 2388.1 & 1665.3 & 4052.2 & 378.7 & 4052.2 & 378.7 \\
\hline & $\begin{array}{l}\text { Ecological } \\
\text { environment }\end{array}$ & 31,325 & 31,325 & 0 & 0 & 0 & 0 & 0 & 0 & 0 & 0 & 0 \\
\hline & Total & 209,711 & 207,853 & 1858 & $38,139.8$ & 7850 & $14,142.6$ & 6370.6 & $23,997.2$ & 1479.4 & $23,997.2$ & 1479.4 \\
\hline \multirow{6}{*}{ Scheme 6} & Industrial & 77,733 & 76,657 & 1076 & $27,184.4$ & 5436.9 & $11,047.3$ & 4789.9 & $16,137.1$ & 647 & 16,981 & 1012.9 \\
\hline & Urban domestic & 48,815 & 48,815 & 0 & 3920.5 & 294 & 1593.2 & 259.1 & 2327.3 & 34.9 & 2449 & 54.8 \\
\hline & Rural domestic & 8093 & 8093 & 0 & 846.1 & 183.3 & 343.9 & 161.5 & 502.2 & 21.8 & 528.5 & 34.2 \\
\hline & Agricultural & 43,745 & 43,280 & 465 & 6465.4 & 2026.6 & 2627.4 & 1785.4 & 3838 & 241.2 & 4038.7 & 377.6 \\
\hline & $\begin{array}{c}\text { Ecological } \\
\text { environment }\end{array}$ & 31,325 & 31,325 & 0 & 0 & 0 & 0 & 0 & 0 & 0 & 0 & 0 \\
\hline & Total & 209,711 & 208,170 & 1541 & $38,416.4$ & 7940.8 & $15,611.8$ & 6995.9 & $22,804.6$ & 944.9 & $23,997.2$ & 1479.4 \\
\hline \multirow{6}{*}{ Scheme 7} & Industrial & 77,733 & 77,528 & 205 & 27184.4 & 5436.9 & 9582.3 & 4407 & $16,550.2$ & 819.5 & $16,950.9$ & 1003.8 \\
\hline & Urban domestic & 48,815 & 48,815 & 0 & 3920.5 & 294 & 1301.9 & 224.5 & 2248.6 & 41.8 & 2303 & 51.1 \\
\hline & Rural domestic & 8093 & 8093 & 0 & 846.1 & 183.3 & 310.6 & 154.8 & 536.5 & 28.7 & 549.5 & 35.3 \\
\hline & Agricultural & 43,745 & 42,412 & 1333 & 6432.8 & 2016.4 & 2370.7 & 1708.9 & 4094.7 & 317.7 & 4193.8 & 389.2 \\
\hline & $\begin{array}{c}\text { Ecological } \\
\text { environment }\end{array}$ & 31,325 & 31,325 & 0 & 0 & 0 & & & 0 & & 0 & 0 \\
\hline & Total & 209,711 & 208,173 & 1538 & $38,383.8$ & 7930.6 & $13,565.6$ & 6495.1 & $23,429.9$ & 1207.8 & $23,997.2$ & 1479.4 \\
\hline \multirow{6}{*}{ Scheme 8} & Industrial & 77,733 & 77,733 & 0 & 26,226 & 5245.2 & 10,583 & 4843.9 & 15,643 & 401.3 & $16,961.1$ & 1004.6 \\
\hline & Urban domestic & 48,815 & 48,815 & 0 & 3555.2 & 266.6 & 1434.6 & 246.3 & 2120.6 & 20.3 & 2299.2 & 51.1 \\
\hline & Rural domestic & 8093 & 8093 & 0 & 859 & 186.1 & 346.7 & 171.9 & 512.3 & 14.2 & 555.5 & 35.6 \\
\hline & Agricultural & 43,745 & 42,212 & 1533 & 6274 & 1966.6 & 2609.1 & 1871.6 & 3665 & 95 & 4181.4 & 388.1 \\
\hline & $\begin{array}{c}\text { Ecological } \\
\text { environment }\end{array}$ & 31,325 & 31,325 & 0 & 0 & 0 & 0 & 0 & 0 & 0 & 0 & 0 \\
\hline & Total & 209,711 & 208,178 & 1533 & $36,914.2$ & 7664.5 & $14,973.3$ & 7133.7 & 21940.9 & 530.8 & $23,997.2$ & 1479.4 \\
\hline
\end{tabular}




\section{Discussion}

\subsection{Analysis of Water Consumption Distribution Results}

(1) Analysis from the perspective of the water shortage

With the increase of various measures in each distribution scene, the total water shortage of Zhengzhou in 2030 decreased from $24,779 \times 10^{4} \mathrm{~m}^{3}$ (Scheme 1) to $1533 \times 10^{4} \mathrm{~m}^{3}$ (Scheme 8), and the water shortage rate decreased from $10.9 \%$ to $0.74 \%$, which alleviated the water shortage situation of Zhengzhou greatly. The change trend in the water shortage under the $50 \%$ guarantee rate of Zhengzhou in 2030 is shown in Figure 1.

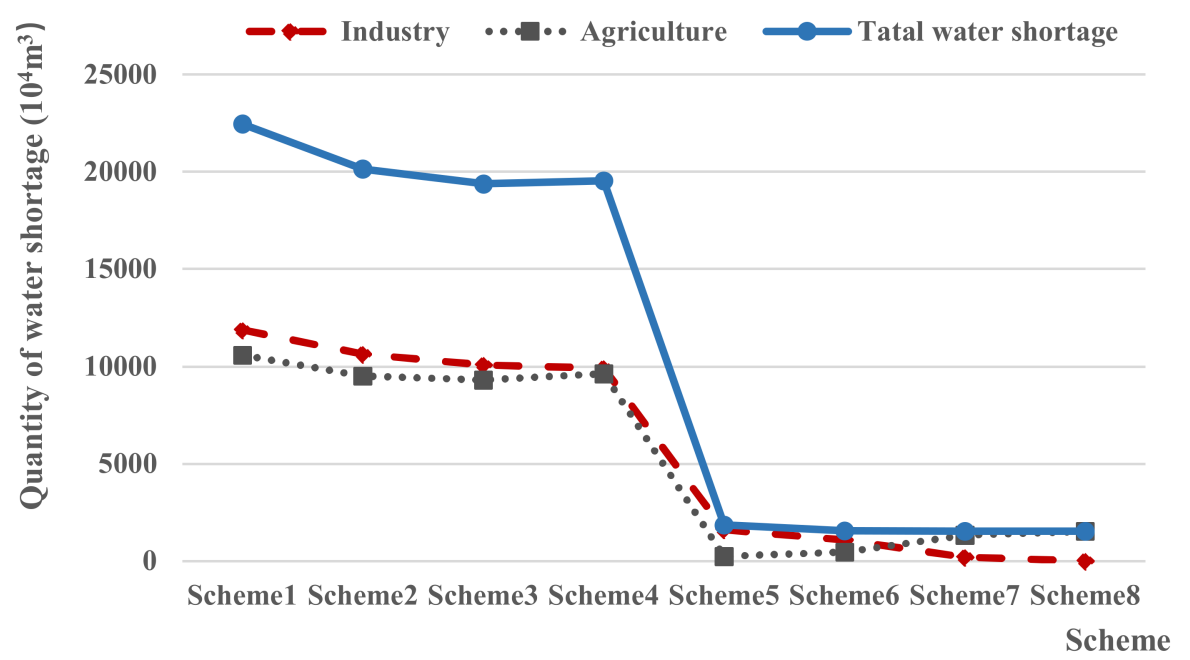

Figure 1. Water shortage change trend of each scheme and water use sector under the $50 \%$ guarantee rate of Zhengzhou in 2030.

Taking scheme 5 as an example, although the implementation of water-saving measures has alleviated the contradiction of the water supply and demand to a certain extent, the total water supply in Zhengzhou has not reached the maximum water supply capacity from the water supply source fully. This is because, under the certain circumstances of the sewage treatment level and pollutant treatment investment, the restraint of the pollutant carrying capacity in the water function area limits the water use quantity of each production and domestic sector directly. For scheme 7 and 8 (compared to scheme 5 and 6), due to the improvement in the sewage treatment level and pollutant reduction cost, the constraint in the pollutant reduction funding restrictions on the pollution discharge amount, by the high-polluting industrial water sector, is weakened to some extent. Water is preferentially distributed to the industrial water sector, with higher efficiency, for water consumption, which increased water shortages in the agricultural sector to some extent. However, with the increase in the scheme's different measures, the water shortage of Zhengzhou city in 2030 presents a decreased trend integrally.

(2) Analysis from the perspective of the water use structure

As shown in Figure 2, domestic and ecological water is satisfied in different distribution schemes, which reflects the domestic water constraint and ecological objective proposal in the model's settings and the calculation methods of the model's solution are indirectly effective. In addition, if the pollutant reduction cost and pollutant carrying capacity limitation are not considered, industrial water use is given priority. However, for scheme 1 to scheme 8 , due to the restrictions from the pollutant reduction costs and the pollutant-carrying capacity of the water functional area, water distribution decreases water consumption in industrial sectors in order to reduce pollutant discharge with a corresponding reduction in treatment costs. Thus, to achieve the goal of limiting the pollutant carrying factor in water 
functional areas, the reduced water amount is allocated to the agricultural water. Due to the increase in the allocation measures of each scheme, the ratio of the water content in each sector to the total water distribution amount also changes accordingly, which reflects the role of the model in targeting the setting and measure regulations.

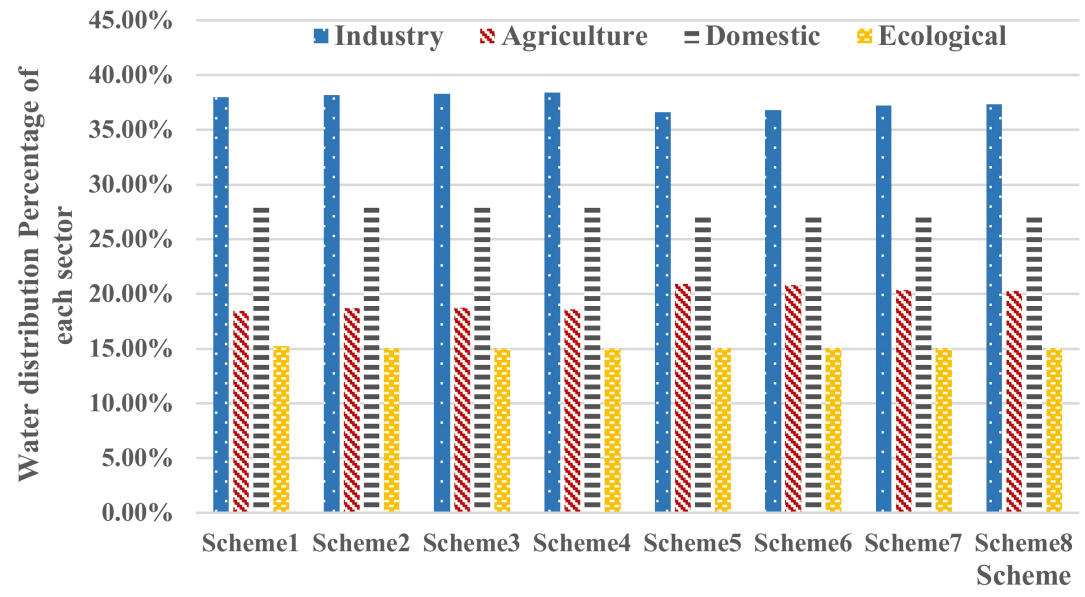

Figure 2. Water structure diagram of each scheme and water use sector under the $50 \%$ guarantee rate of Zhengzhou in 2030.

\subsection{Analysis of Pollutant Carrying Capacity Distribution Results}

(1) Analysis from the perspective of pollutants into the river

The amount of pollutant in the river decreased from 23,997.2 $\mathrm{t}(\mathrm{COD})$ and $1479.4 \mathrm{t}\left(\mathrm{NH}_{3}-\mathrm{N}\right)$ in scheme 1 to $21,940.9 \mathrm{t}(\mathrm{COD})$ and $530.8 \mathrm{t}\left(\mathrm{NH}_{3}-\mathrm{N}\right)$ in scheme 8 , under the $50 \%$ guarantee rate of Zhengzhou in 2030, which shows a decrease trend on the whole, and meets the requirements of the pollutant-carrying capacity in the water functional area and each water use sector.

As the allocated water amount increases, the pollutant discharged amount of each water sector increases accordingly, but, with the increase in various sewage treatments and pollutant reduction measures in different schemes, the pollutant reduction capacity is improved significantly. Therefore, the final amount of pollutants into the river in each scheme also decreased significantly. The pollutants into the river in various sectors showed an overall decrease trend from schemes 1-8 (as shown in Figures 3-5), which also verifies the mutual influence and restriction between water allocation measures and pollutant treatment measures in the model.

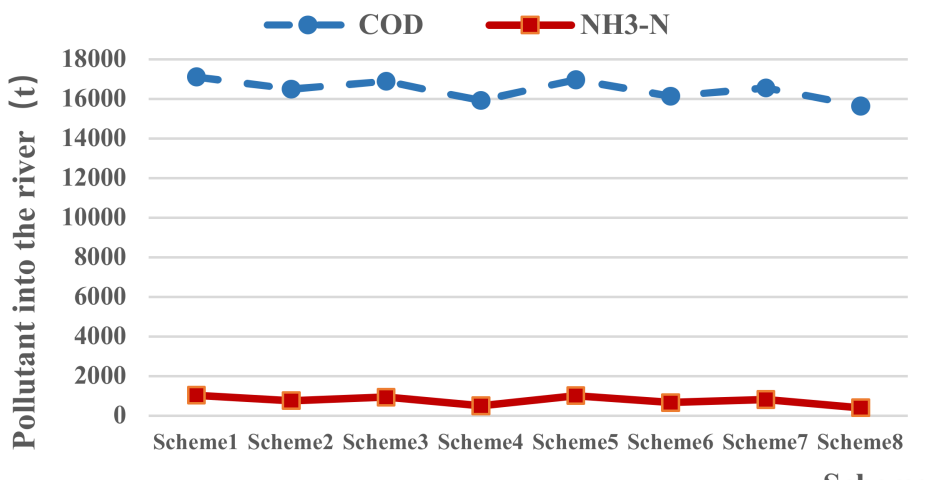

Scheme

Figure 3. Changing trends of pollutants into the river by industrial water use sectors of Zhengzhou in 2030 . 


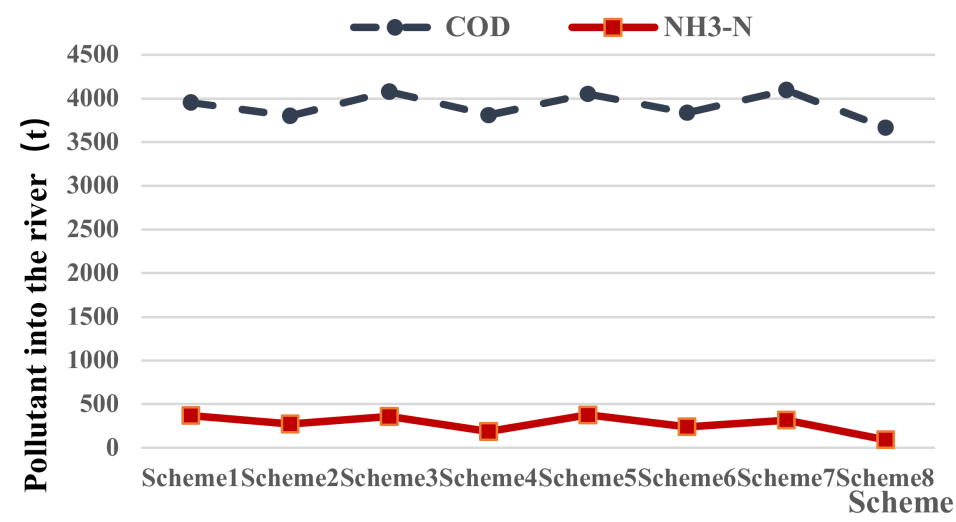

Figure 4. Changing trends of pollutants into the river from agricultural water use sectors of Zhengzhou in 2030.

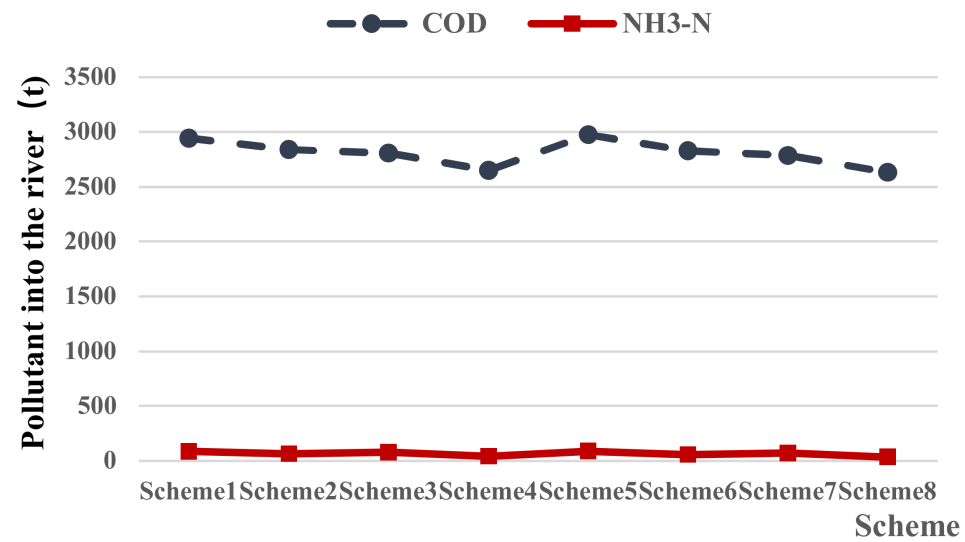

Figure 5. Changing trends of pollutants into the river from domestic water use sectors of Zhengzhou in 2030 .

(2) Analysis from the perspective of the pollutant-carrying capacity allocation structure

Take scheme 1 and 2 as examples. Scheme 2 increases the pollutant reduction funding on the basis of scheme 1 , which reduces the restrictions of water supply constraints for the high-polluting sectors. Industries, from pollutant reduction funding, means that water supply tends to be allocated to industries, whose unit water use efficiency is high. Therefore, the pollutant carrying capacity of industrial water sectors increased in comparison to agricultural and domestic water sectors, which reduced (as shown in Figure 6). To sum up, while increasing the water supply to solve water shortage, it is necessary to adjust the water use structure reasonably and to reduce water consumption in high-pollutant discharge sectors appropriately in order to control the pollutant discharge and the reduction amount directly. At the same time, it is necessary to increase the construction of sewage treatment facilities so that the pollutant to be treated can be treated effectively and the unity of water resource utilization and water environment protection can be achieved.

\subsection{Analysis of Joint Optimal Allocation Results of Water Consumption and Pollutant-Carrying Capacity}

According to the objective function and the calculation methods of various benefits in chapter 2, the joint optimal allocation benefits that are realized by different distribution schemes are calculated, as shown in Table 15. Since the dimensional level of the positive benefit and negative benefit are clearly different, the comparative analysis is carried out on them, respectively, as shown in Figures 7 and 8. 


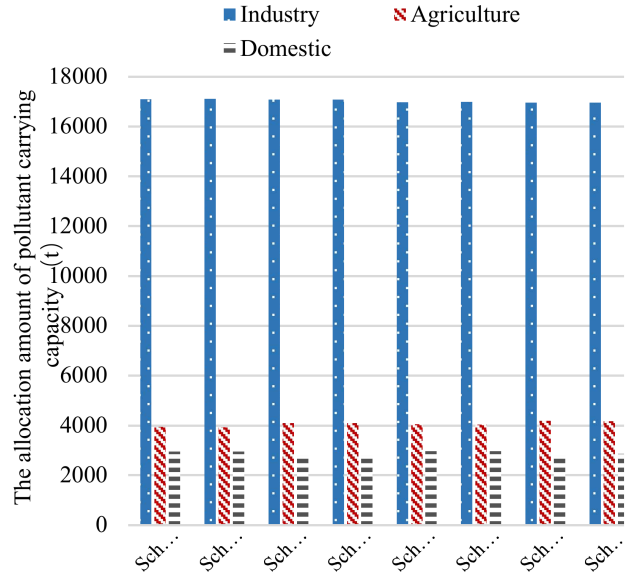

(a) Pollutant COD

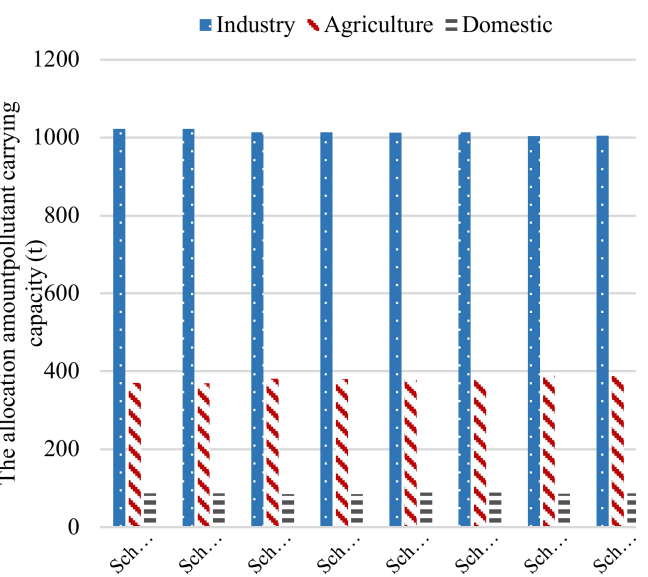

(b) Pollutant $\mathrm{NH}_{3}-\mathrm{N}$

Figure 6. Pollutant capacity distribution structure diagram of each scheme and water use sector of Zhengzhou in 2030.

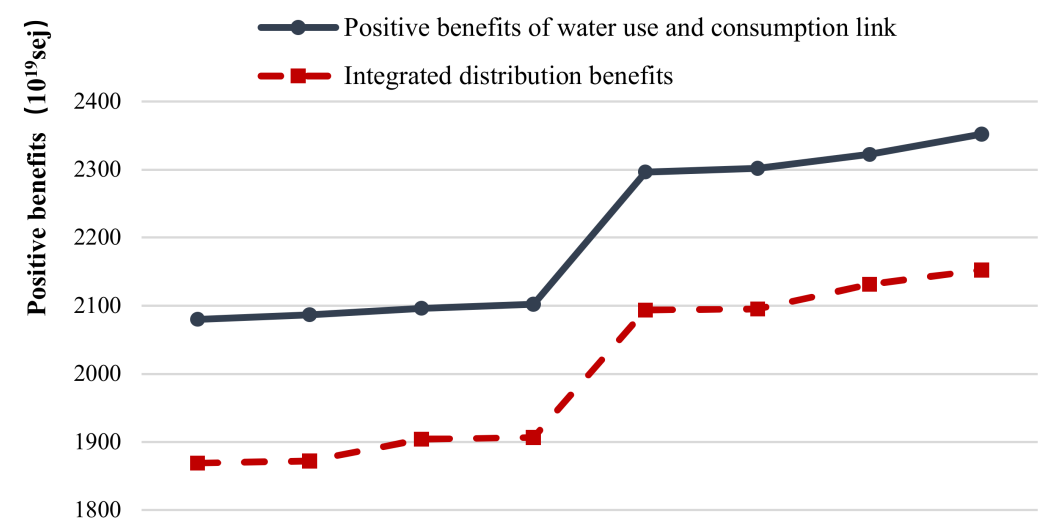

Scheme1 Scheme2 Scheme3 Scheme4 Scheme5 Scheme6 Scheme7 Scheme8

Scheme

Figure 7. Positive benefits comparison of each scheme under the $50 \%$ guarantee rate of Zhengzhou in 2030.

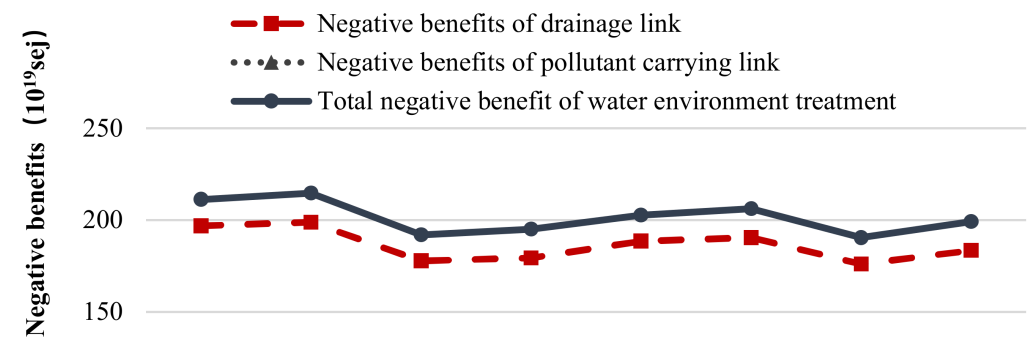

100

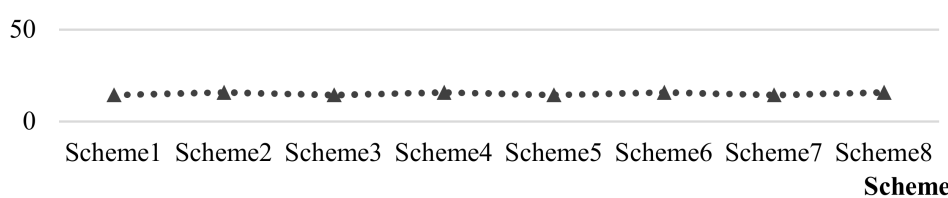

Figure 8. Negative benefits comparison of each scheme under the $50 \%$ guarantee rate of Zhengzhou in 2030. 
Table 15. Joint optimal allocation benefits comparison of different schemes under the $50 \%$ guarantee rate of Zhengzhou in 2030 (unit: $10^{19}$ sej).

\begin{tabular}{|c|c|c|c|c|c|c|c|c|}
\hline Benefit & Scheme 1 & Scheme 2 & Scheme 3 & Scheme 4 & Scheme 5 & Scheme 6 & Scheme 7 & Scheme 8 \\
\hline Positive benefits of water use and consumption link & 2256.83 & 2264.09 & 2274.1 & 2280.49 & 2513.79 & 2519.68 & 2541.95 & 2548.16 \\
\hline Negative benefits of drainage link & -150.81 & -152.31 & -121.66 & -122.81 & -140.12 & -141.63 & -122 & -123.29 \\
\hline Negative benefits of pollutant carrying link & -17.22 & -18.66 & -17.22 & -18.66 & -17.22 & -18.66 & -17.22 & -18.66 \\
\hline
\end{tabular}


As shown in Table 15 and Figures 7 and 8, the joint optimal allocation benefits showed an overall increasing trend in Schemes 1-8. In order to compare the effects of various distribution measures on the joint optimal allocation results, the analysis is as follows.

(1) Analysis of the measures from the water demand side (schemes 5-8 vs. schemes 1-4)

Under the moderate water-saving scheme in 2030, the total water shortage of Zhengzhou is $19,552 \times 10^{4} \mathrm{~m}^{3}$. After the implementation of the strengthening water-saving scheme, the total water shortage in Zhengzhou was reduced to $1533 \times 10^{4} \mathrm{~m}^{3}$.

Under the circumstance that all other measures in schemes 1-4 remain unchanged, only strengthening water-saving is implemented in schemes $5-8$. Then, on the one hand, the unit water efficiency is improved, the shortage in water supply is alleviated, and the water use guarantee rate of each sector is improved. On the other hand, due to the implementation of water-saving measures, the water supply amount of various sectors is reduced, which leads to the decrease in the sewage discharge amount and pollutant amount into the river in industrial and other high-discharge sectors directly, which results in a corresponding decrease in direct sewage discharge and sewage treatment costs. Therefore, the joint optimal allocation benefits in schemes 5-8 are significantly higher than that of schemes 1-4.

To sum up, the implementation of strengthened water-saving measures alleviate the contradiction between the supply and demand for water resources, while adjusting the water supply structure reduces the water supply of high-pollutant discharge sectors appropriately, reduces the final pollutant amount into the river indirectly, and decreases the allocation amount of the pollutant-carrying capacity. Therefore, water-saving measures are a powerful means to effectively alleviate the contradiction between supply and demand for water resources and the deterioration of the water environment.

(2) Analysis from the measures from the sewage treatment side (schemes 3-4 vs. schemes 1-2)

Scheme 3-4 improve the sewage treatment level on the basis of schemes 1-2 even though it increases the sewage treatment cost to some extent. On the one hand, it reduced the direct pollutant amount into rivers in industrial and domestic sectors greatly. On the other hand, it also reduced the pollutant reduction amount and had corresponding reduction costs. Therefore, the joint optimal allocation benefits still improved, correspondingly, from $1868.98 \times 10^{19}$ sej (scheme 1 ) and $1873.14 \times 10^{19}$ sej (scheme 2) to $1904.35 \times 10^{19}$ sej and $1908.54 \times 10^{19}$ sej in schemes 3 and 4 , respectively. Thus, improving the sewage treatment level and paying attention to the construction of sewage treatment facilities can more effectively treat the pollutants discharged from production and living, realize more comprehensive water resources utilization benefits, and realize the coordination and unification of water resources utilization and water environmental protection.

(3) Analysis from the measures of the pollutant reduction funds side (scheme 7 vs. 8)

After the restriction on pollutant reduction investment is added, the pollutant reduction capacity is reduced indirectly, and the water allocation will reduce the quantity of water distribution in high-emission sectors correspondingly, in order to realize the constraint of pollutant-carrying capacity in water functional areas. Therefore, the quantity of water distribution in industrial water sectors, whose pollutant discharge amount per unit of water is the largest, has the clearest decrease. The reduced water amount is allocated to agricultural and other water sectors accordingly.

On the basis of scheme 7 , the pollutant reduction funding level is improved in scheme 8 , which reduces the restrictions on the water structure by reducing the funding limit, and makes the water supply more likely to be allocated to industrial and domestic water sectors, which leads to an increase in the pollution loss by direct discharge loss and sewage treatment cost, but the unit water use efficiency of the industrial and domestic water sector is significantly higher than the agricultural water sector. Therefore, the increasing trend of positive benefits in the water consumption link is clearer, and the joint optimal allocation benefit realized in scheme 8 is, in general, still higher than that in scheme 7. 
In conclusion, with the model optimization objective as the criterion, scheme 8 is recommended as the optimal solution under the 50\% guarantee rate in Zhengzhou in 2030.

\subsection{Comparative Analysis of the Joint Optimal Allocation Results of Water Consumption and Pollutant-Carrying Capacity with the Traditional Allocation Method}

To identify the feasibility and advantages of joint optimal allocation methods of water consumption and pollutant carrying capacity based on emergy theory, the above joint distribution results are compared with those obtained by traditional water resources allocation. The reverse restriction of pollutant carrying capacity limits to the water amount allocation and benefits evaluation is expounded. The necessity of joint optimal allocation is verified. The results obtained by traditional methods consulted the results in "Study on the water resources allocation based on secondary distribution in Zhengzhou metropolitan area," [23] and the comparison and analysis between the joint optimal allocation results based on emergy theory and traditional results in 2030 are shown in Table 16.

Table 16. Allocation results' comparison of an optimal scheme of Zhengzhou in 2030.

\begin{tabular}{|c|c|c|c|c|c|c|c|}
\hline \multirow[t]{2}{*}{$\begin{array}{l}\text { Allocation } \\
\text { Methods }\end{array}$} & \multirow{2}{*}{$\begin{array}{l}\text { Allocation } \\
\text { Water Quantity } \\
\qquad\left(10^{4} \mathrm{~m}^{3}\right)\end{array}$} & \multicolumn{2}{|c|}{$\begin{array}{c}\text { Corresponding } \\
\text { Pollution Discharge }(t)\end{array}$} & \multicolumn{2}{|c|}{$\begin{array}{l}\text { Pollutant Carrying } \\
\text { Capacity }(t)\end{array}$} & \multicolumn{2}{|c|}{$\begin{array}{c}\text { Satisfaction Degree of } \\
\text { Pollution Carrying } \\
\text { Capacity }\end{array}$} \\
\hline & & COD & $\mathrm{NH}_{3}-\mathrm{N}$ & COD & $\mathrm{NH}_{3}-\mathrm{N}$ & COD & $\mathrm{NH}_{3}-\mathrm{N}$ \\
\hline $\begin{array}{l}\text { Emergy } \\
\text { method }\end{array}$ & 205,779 & $21,940.9$ & 530.8 & \multirow[t]{2}{*}{$23,997.2$} & \multirow[t]{2}{*}{1479.4} & $\sqrt{ }$ & $\sqrt{ }$ \\
\hline $\begin{array}{l}\text { Traditional } \\
\text { method }\end{array}$ & 262,796 & $46,888.6$ & 9761.1 & & & $x$ & $x$ \\
\hline
\end{tabular}

Note: $\sqrt{ }$ means satisfied, $\times$ means not satisfied.

Compared with the traditional water resources allocation, the joint optimal allocation based on emergy theory in this paper focus on the mutual restriction relations between water quantity and pollutants discharge into the river, realizes the reverse regulation of water consumption and pollutant carrying capacity in the joint distribution process, and ensure to obtain the most optimal joint allocation scheme on the premise of meeting the pollutant carrying capacity of water function areas. On the contrary, the traditional allocation of water resources only aims at the maximum benefit by ignoring the limitation of the pollution carrying capacity, which may not meet the needs of an ecological environment. Therefore, the satisfaction degree of pollution carrying capacity under the optimal water allocation of two methods is compared and analyzed. The results are shown in Table 16.

As shown in Table 16, the joint optimal allocation method in this paper limits from water supply and pollution carrying. The ultimate limit of pollution carrying capacity reverses the initial water supply, and then achieve maximum benefits of joint allocation in ensuring to meet the pollution carrying capacity constraints, and satisfy the efficient utilization of water resources and water environmental protection targets simultaneously. However, the traditional method takes no account of the limitation and regulation function of pollutant carrying capacity. It only regards the final biggest benefit as a target, so its allocation water quantity is significantly greater than the emergy method. Then the corresponding pollutant discharge of $\mathrm{COD}$ and $\mathrm{NH}_{3}-\mathrm{N}$ calculated according to the allocation water quantity are higher, far beyond the pollution carrying capacity of the water function area. This is not conducive for the sustainable development of water resources' ecological economic system. Therefore, it is necessary to carry out the research on the pollution carrying capacity constraint and its joint allocation in the optimal allocation of water resources.

\section{Conclusions}

Based on the emergy theory of ecological economics, the thought frame, model method, and overall application of the joint optimal allocation of regional water consumption and pollutant carrying 
capacity are studied, and enriches existing research ideas and technical methods of the optimal allocation of water resources. The main conclusions are as follows.

(1) Ecological economics emphasizes the coupling of the natural ecological system and social economy system. This study is based on the emergy theory of ecological economics with regard to the joint optimal allocation process of regional water consumption and pollutant-carrying capacity as the material circulation and energy conversion process, and takes the water consumption and pollutant-carrying capacity as the direct configuration elements at the same time. This can reflect the restriction relationship and reverse the regulation mechanism between them profoundly, as well as the theoretical basis of sustainable utilization and management research of water resources.

(2) By analyzing the water quality and water quantity conversion process of "water supply-water use and consumption-drainage-pollutant carrying" links, the positive and negative effects, and their manifestations of water on the economic, social, and ecological environment, can be described comprehensively. The results show that the components of the joint optimal allocation benefits include: (1) benefits of the water use and consumption link (industrial and agricultural products benefits, labor recovery benefit, dilution purification benefits, cooling and humidifying benefits, carbon fixation and oxygen release benefits, spraying and dust removal benefits), (2) benefits of the drainage link (water quality pollution loss caused by direct discharge and sewage treatment loss), and (3) benefits of the pollutant carrying link (pollutant reduction costs). Then, the emergy quantitative analysis technology can realize the unified quantitative evaluation of the economic, social, and ecological benefits in the process of the joint optimal allocation process of regional water consumption and pollutant-carrying capacity.

(3) In the process of establishing the joint optimal allocation model of regional water consumption and pollutant-carrying capacity, one of the key links is to construct the interaction relationship between water consumption and pollutants into the river, according to the physical contact between sewage discharge and pollutant discharge into the river and the water consumption allocated to each department in order to realize the coupling between water quantity and water quality. Then, taking the maximum emergy net benefit as the objective function cannot only realize the unified quantification of the economic, social, and ecological benefits of different sectors in the process of joint optimal allocation, but can also change the traditional multi-objective model of water resource optimal allocation into a single-objective model to avoid the difficulty of determining the multi-objective weight.

(4) The example verification of Zhengzhou city shows that, with the continuous improvement of various control measures and inputs, the contradiction between water supply and demand in Zhengzhou has been alleviated. The constraint of the pollutant-carrying capacity distribution in the water function areas was satisfied to the maximum extent, and the maximum joint optimal allocation benefit was achieved. This shows that the pollutant carrying capacity limitation restricts water supply from the source reversely, and there is a clear mutual influence and restriction relationship between the water distribution and pollutant carrying capacity distribution, which verifies the joint optimal allocation model of regional water consumption and pollutant carrying capacity. Its solution method in this paper is effective and feasible.

Author Contributions: This paper represents a result of collaborative teamwork. Z.W. developed the concept and supervised the work; X.G. conceived of the study, performed model validation, and drafted the manuscript; C.L. and M.G. participated in the design of the study and coordination and revised the manuscript; C.G. and Y.L. collected the data and revised the manuscript; and X.W. provided constructive suggestions and revised the manuscript. All authors have read and agreed to the published version of the manuscript.

Funding: The National Natural Science Foundation of China (No. NSCF-51909240 and No. NSCF-51739009) funded this research.

Acknowledgments: The authors are grateful to colleagues and friends who shared their meteorological and hydrological data with us. We also thank two reviewers for insightful comments that improved an earlier version of this manuscript.

Conflicts of Interest: The authors declare no conflicts of interest. 


\section{References}

1. Li, Y. Basic function of the reasonable allocation of water resources management in the implementation of the most rigorous system. China Water Resour. 2010, 20, 26-28. (In Chinese)

2. Wang, H.; You, J. Advancements and development course of research on water resources deployment. SHUILIXUEBAO 2008, 10, 1168-1175. (In Chinese)

3. Jiang, Z.; Yang, J.; Ren, X. Optimal allocation of water resources based on 'three red lines' and se-d EA model. Water Sav. Irrig 2016, 11, 81-84. (In Chinese)

4. Yan, D.; Luo, X.; Wang, H.; Qin, D.; She, J. The Dual Gross Control of Rivers Based on the Rational Water Resources Allocation-A Case Study on Tangshan. J. Nat. Resour. 2007, 22, 3-10. (In Chinese)

5. Liu, B.; Chen, X.; Jiang, T. Water resources allocation model based on the dual-control of water quantity and quality. Adv. Water Sci. 2009, 20, 55-59. (In Chinese)

6. You, J.; Xue, X.; Nu, C. Concept and study progress of joint regulation on water quantity and quality. Water Resour. Hydropower Eng. 2010, 41, 7-9, 18. (In Chinese)

7. Fan, Q.; Wang, L.; Li, X.; Qin, J. Discussion on water demand management method based on pollutant discharge limits. Water Sav. Irrig. 2012, 1, 37-38, 43. (In Chinese)

8. Zhang, W. Study on the overall optimal allocation and countermeasures of regional water quantity and quality. Ph.D. Thesis, China University of Mining and Technology, Beijing, China, 2016. (In Chinese).

9. Wu, Z.; Lv, C.; Hu, C.; Guan, X. Research on the Analysis Method and Application of Ecological Economic Value Based on Emergy Theory; Science Press: Beijing, China, 2013. (In Chinese)

10. Wu, Z.; Di, D.; Lv, C.; Guo, X.; Wang, H. Defining and evaluating the social value of regional water re-sources in terms of emergy. Water Policy 2019, 21, 73-90. [CrossRef]

11. Dong, M. Study on Integrated Optimal Macro-Distribution Model of Regional Water Consumption and Pollutant Carrying Capacity. Master's Thesis, Zhengzhou University, Zhengzhou, China, 2014. (In Chinese).

12. Lan, S.; Qin, P.; Lu, H. Emergy in Ecosystems; Chemical industry press: Beijing, China, 2002. (In Chinese)

13. Guo, X.; Wu, Z.; Wang, H. Emergy evaluation of positive and negative effects of water utilization in regional agricultural production system. Adv. Sci. Technol. Water Resour. 2016, 36, 1-5. (In Chinese)

14. Tian, G. Study on Emergy Evaluation Method of the Value of Ecological Water Use Based on Material Cycle. Master's Thesis, Zhengzhou University, Zhengzhou, China, 2016. (In Chinese).

15. Li, C.; Yuan, Z.; Ren, H.; Fu, Z.; Cai, Z. Effects of water spray control on fugitive dusts originated from raw material piles in steel plants. China Power Sci. Technol. 2009, 15, 78-83. (In Chinese)

16. Zhao, P.; Feng, Y.; Jing, J.; Han, B.; Bi, X.; Zhu, T.; Zhang, X. Characteristics and control indicators of fugitive dust from building construction sites. Acta Sci. Circumstantiate 2009, 29, 1618-1623. (In Chinese)

17. Zhao, G. Ecological Economics; Chemical industry press: Beijing, China, 2008. (In Chinese)

18. Wu, Z.; Guo, X.; Lv, C.; Wang, H.; Di, D. Study on the quantification method of water pollution ecological compensation standard based on emergy theory. Ecol. Indic. 2018, 92, 189-194. [CrossRef]

19. Lv, C.; Wu, Z. Emergy analysis of regional water ecological-Economic system. Ecol. Eng. 2009, 35, 703-710. [CrossRef]

20. Odum, H.T.; Odum, E.C. Energy Analysis Overview of Nations; Working Paper WP-83-82; International Institute for Applied Systems Analysis: Laxenburg, Austria, 1983; p. 421.

21. Wu, Z.; Guo, X.; Di, D.; Lv, C.; Wang, H. Water efficiency evaluation of a regional water scheme-Zhengzhou, China, using a water ecological-economic system (WEES) and based on emergy theory. Water Sci. Technol. Water Supply 2016, 17, 674-687. [CrossRef]

22. Guo, X. The Integrated Distribution Study of Regional Water Consumption and Pollutant Carrying Capacity Based on Emergy Theory. Ph.D. Thesis, Zhengzhou University, Zhengzhou, China, 2018. (In Chinese).

23. $\mathrm{Mu}, \mathrm{L}$. Study on the Water Resources Allocation Based on Secondary Distribution in Zhengzhou Metropolitan Area. Master's Thesis, Zhengzhou University, Zhengzhou, China, 2017. (In Chinese).

(C) 2020 by the authors. Licensee MDPI, Basel, Switzerland. This article is an open access article distributed under the terms and conditions of the Creative Commons Attribution (CC BY) license (http://creativecommons.org/licenses/by/4.0/). 